\title{
Acute Social Stress Engages Synergistic Activity of \\ Stress Mediators in the VTA to Promote Pavlovian
}

\section{Reward Learning}

Jorge Tovar-Diaz ${ }^{1,2}$, Matthew B. Pomrenze ${ }^{2,3}$, Bahram Pahlavan ${ }^{1,2}$, Russell Kan ${ }^{4}$,

Michael R. Drew ${ }^{1,5}$, and Hitoshi Morikawa ${ }^{1,2, *}$

${ }^{1}$ Department of Neuroscience

${ }^{2}$ Waggoner Center for Alcohol and Addiction Research

${ }^{3}$ Division of Pharmacology and Toxicology

${ }^{4}$ Department of Biomedical Engineering

${ }^{5}$ Center for Learning and Memory

University of Texas at Austin, Austin, Texas 78712, USA

*Correspondence: morikawa@utexas.edu 


\section{ABSTRACT}

2 Stressful events rapidly trigger activity-dependent synaptic plasticity in certain brain

3 areas, driving the formation of aversive memories. However, it remains unclear how

4 stressful experience affects plasticity mechanisms to regulate learning of appetitive

5 events, such as intake of addictive drugs or palatable foods. Using rats, we show that two

6 acute stress mediators, corticotropin-releasing factor (CRF) and norepinephrine (NE),

7 enhance plasticity of NMDA receptor-mediated glutamatergic transmission in the ventral

8 tegmental area (VTA) through their differential effects on inositol 1,4,5-triphosphate

9 ( $\left.\mathrm{IP}_{3}\right)$-dependent $\mathrm{Ca}^{2+}$ signaling. In line with this, acute social defeat stress engages

10 convergent CRF and NE signaling in the VTA to enhance learning of cocaine-paired

11 cues. Furthermore, defeat stress enables learning of a food-paired cue with no delay

12 between the cue onset and food delivery. We propose that acute stress mediators

13 synergistically regulate $\mathrm{IP}_{3}-\mathrm{Ca}^{2+}$ signaling in the VTA to promote appetitive Pavlovian

14 conditioning, likely enabling learning of cues with no predictive value. 


\section{INTRODUCTION}

16 Stressor intensity, controllability, and duration are major determinants for regulation of

17 future stress coping behavior and diverse cognitive functions (Koolhaas et al., 2011). In

18 general, acute mild-to-moderate stress energizes adaptive cognitive processes and

19 behaviors in the short run while severe/uncontrollable/chronic stress leads to maladaptive

20 changes in brain function, including hippocampus-dependent learning and memory and

21 other higher order cognitive processes (Chattarji et al., 2015; Kim et al., 2015; McEwen,

22 2007). As these cognitive functions are primarily declarative and studied outside the

23 context of emotional valence, less is known about the impact of stress on reward-driven

24 learning and behavior [see (Rodrigues et al., 2009) for stress effect on fear learning]. In

25 this regard, stress is a well-known risk factor for the development of addiction, which can

26 be viewed as a maladaptive form of reward learning (Sinha, 2008). While many studies

27 have linked stress to addiction through long-term influence of glucocorticoids in the

28 brain, stress can also exert rapid effects through the release of corticotropin-releasing

29 factor (CRF) and norepinephrine (NE) (Joels et al., 2011; Maras and Baram, 2012).

30 Immediate impact of stress has been studied extensively in intensification and/or

31 reinstatement of drug seeking (Mantsch et al., 2016; Polter and Kauer, 2014); however it

32 is not clear how stressful experience acutely regulates the acquisition of addictive 33 behavior.

34 Dopamine (DA) neurons in the ventral tegmental area (VTA) play a key role in

35 reward learning (Schultz, 2015). These neurons display transient burst firing in response

36 to primary rewards (e.g., palatable food), while addictive drugs induce repetitive DA

37 neuron bursting via pharmacological actions (Covey et al., 2014; Keiflin and Janak, 
38 2015). During cue-reward conditioning, DA neurons "learn" to respond to reward-

39 predicting cues, thereby encoding the positive emotional/motivational valence of those

40 cues (Cohen et al., 2012; Schultz, 1998; Stauffer et al., 2016). Glutamatergic inputs onto

41 DA neurons drive burst firing via activation of NMDA receptors (Overton and Clark,

42 1997; Paladini and Roeper, 2014); thus strengthening of cue-driven NMDA input may

43 contribute to conditioned bursting. We have shown previously that repeated pairing of

44 cue-like glutamatergic input stimulation with reward-like bursting leads to long-term

45 potentiation (LTP) of NMDA transmission (LTP-NMDA) in DA neurons (Harnett et al.,

46 2009). LTP induction requires amplification of burst-evoked $\mathrm{Ca}^{2+}$ signals by preceding

47 activation of metabotropic glutamate receptors (mGluRs) coupled to the generation of

48 inositol 1,4,5-triphosphate $\left(\mathrm{IP}_{3}\right)$. Here, $\mathrm{IP}_{3}$ receptors $\left(\mathrm{IP}_{3} \mathrm{Rs}\right)$ detect the coincidence of $\mathrm{IP}_{3}$

49 generated by glutamatergic input activity and burst-driven $\mathrm{Ca}^{2+}$ entry. Mechanistically,

$50 \mathrm{IP}_{3}$ enhances $\mathrm{Ca}^{2+}$ activation of $\mathrm{IP}_{3} \mathrm{Rs}$, thereby promoting $\mathrm{Ca}^{2+}$-induced $\mathrm{Ca}^{2+}$ release from

51 intracellular stores (Taylor and Laude, 2002). In this study, we demonstrate how CRF and

52 NE actions in the VTA regulate plasticity of NMDA transmission and the impact of acute

53 stress on Pavlovian cue-reward learning.

\section{RESULTS}

\section{Acute social stress enhances cocaine-associated cue learning}

57 We first investigated how acute social defeat stress affects the learning of cocaine-

58 associated cues using a conditioned place preference (CPP) paradigm. Rats underwent

5930 -min social defeat ( $\sim 5 \mathrm{~min}$ of direct contact/defeat followed by $\sim 25 \mathrm{~min}$ of protected

60 threat), a form of uncontrollable psychosocial stress that elicits strong physiological 
61 responses (Koolhaas et al., 2011). After a 10-min interval, these stressed rats and handled

62 controls were conditioned with a relatively low dose of cocaine $(5 \mathrm{mg} / \mathrm{kg}$, i.p.; Figure

63 1A). This acute defeat stress-cocaine conditioning sequence was limited to a single

64 session to eliminate the confounding effect reflecting persistent influence of stress on

65 CPP acquisition and/or expression (Burke et al., 2011; Chuang et al., 2011; Kreibich et

66 al., 2009; Smith et al., 2012; Stelly et al., 2016). We found that stressed rats developed

67 larger preference for the cocaine-paired chamber compared to control rats (Figure

68 1B,C,F). Both stressed and control rats developed comparable robust CPP with an

69 increase in cocaine dose $(10 \mathrm{mg} / \mathrm{kg})$ during conditioning (Figure 1D-F). Defeat stress

70 failed to affect CPP when cocaine conditioning ( $5 \mathrm{mg} / \mathrm{kg})$ was performed after a

71 prolonged interval $(1.5 \mathrm{hr}$; Figure $1 \mathrm{G}-\mathrm{J})$. These results show that social defeat stress

72 acutely increases the sensitivity to cocaine conditioning.

74 CRF and NE differentially and synergistically promote NMDA plasticity in the VTA

75 Potentiation of NMDA excitation of DA neurons in the VTA may contribute to the

76 learning of cues associated with rewards, including addictive drugs (Stelly et al., 2016;

77 Wang et al., 2011; Whitaker et al., 2013; Zweifel et al., 2008; Zweifel et al., 2009). CRF

78 and NE are the two major mediators of short-term stress effects in the brain (Joels et al.,

79 2011; Maras and Baram, 2012). To gain insight into the mechanisms underlying acute

80 defeat stress-induced enhancement of cocaine conditioning, we examined the effect of

81 CRF and NE on NMDA plasticity using ex vivo VTA slices.

82 Induction of LTP-NMDA requires $\mathrm{mGluR} / \mathrm{IP}_{3}$-dependent facilitation of action

83 potential (AP)-evoked $\mathrm{Ca}^{2+}$ signals (Harnett et al., 2009). $\mathrm{CRF}$ enhances $\mathrm{IP}_{3}-\mathrm{Ca}^{2+}$ 
84 signaling by activation of CRF receptor 2 (CRFR2) in DA neurons (Bernier et al., 2011;

85 Riegel and Williams, 2008; Whitaker et al., 2013), likely via protein kinase A (PKA)-

86 mediated phosphorylation causing increased $\mathrm{IP}_{3} \mathrm{R}$ sensitivity (Wagner et al., 2008). To

87 first confirm this CRF effect, we assessed AP-evoked $\mathrm{Ca}^{2+}$ signals using the size of $\mathrm{Ca}^{2+}$ -

88 sensitive $\mathrm{K}^{+}$currents $\left(\mathrm{I}_{\mathrm{K}(\mathrm{Ca})}\right)$ and a subthreshold concentration of $\mathrm{IP}_{3}(10 \mu \mathrm{M} \cdot \mathrm{mW})$ was

89 photolytically applied into the cytosol for $100 \mathrm{~ms}$ immediately before evoking unclamped

90 APs (see Methods and Materials). Bath application of CRF (100 nM) significantly

91 increased the magnitude of $\mathrm{IP}_{3}$-induced facilitation of $\mathrm{I}_{\mathrm{K}(\mathrm{Ca})}$ (Figure 2A,B).

92 Next, the effect of CRF on LTP-NMDA was tested using an induction protocol

93 consisting of subthreshold $\mathrm{IP}_{3}$ application $(100 \mathrm{~ms})$ prior to simultaneous pairing of a

94 burst (5 APs at $20 \mathrm{~Hz}$ ) with a brief train of synaptic stimulation (20 stimuli at $50 \mathrm{~Hz}$ ), the

95 latter being necessary to induce LTP at specific inputs likely via activating NMDA

96 receptors at those inputs at the time of burst (Harnett et al., 2009; Stelly et al., 2016;

97 Whitaker et al., 2013). While this induction protocol using a low concentration of $\mathrm{IP}_{3}$ (10

$98 \mu \mathrm{M} \cdot \mathrm{mW}$ ) produced relatively small LTP in control solution, robust LTP was induced in

99 the presence of CRF (100 nM; Figure 2C-E).

100 We further examined the effect of CRF on $\mathrm{I}_{\mathrm{K}(\mathrm{Ca})}$ and LTP induction without $\mathrm{IP}_{3}$

101 application. CRF (100-300 nM) had a small effect on $\mathrm{I}_{\mathrm{K}(\mathrm{Ca})}$ (Figure 3A,B), likely

102 reflecting facilitation of small $\mathrm{IP}_{3} \mathrm{R}$-mediated $\mathrm{Ca}^{2+}$-induced $\mathrm{Ca}^{2+}$ release triggered by APs

103 themselves in DA neurons (Cui et al., 2004). Consistent with this observation, CRF failed

104 to enable measurable LTP when simultaneous synaptic stimulation-burst pairing without

105 prior $\mathrm{IP}_{3}$ application was used to induce LTP (Figure 3C-E).

106 DA neurons express $\alpha 1$ adrenergic receptors ( $\alpha 1 \mathrm{ARs)}$ that are coupled to 
107 phospholipase C-mediated $\mathrm{IP}_{3}$ synthesis (Cui et al., 2004; Paladini et al., 2001).

108 Accordingly, bath application of the $\alpha 1 \mathrm{AR}$ agonist phenylephrine $(0.5-1 \mu \mathrm{M})$ increased

$109 \mathrm{I}_{\mathrm{K}(\mathrm{Ca})}$ in a concentration-dependent manner in the absence of exogenous $\mathrm{IP}_{3}$ application

110 (Figure 4A,B). Phenylephrine treatment enabled robust LTP induction with simultaneous

111 synaptic stimulation-burst pairing (Figure 4C-E; see Figure 4-figure supplement 1 for

112 NE effect), in contrast to the ineffectiveness of CRF described above.

113 We next asked if CRF, via CRFR2-mediated $\mathrm{IP}_{3} \mathrm{R}$ sensitization, could enhance

114 the effect of phenylephrine. CRF (100 nM), which had minimal effect on $\mathrm{I}_{\mathrm{K}(\mathrm{Ca})}$ by itself

115 (Figure 3A,B), significantly augmented the small $\mathrm{I}_{\mathrm{K}(\mathrm{Ca})}$ facilitation produced by a low

116 concentration $(0.5 \mu \mathrm{M})$ of phenylephrine (Figure 5A,B), while there was no significant

117 CRF effect on $\mathrm{I}_{\mathrm{K}(\mathrm{Ca})}$ facilitation caused by $1 \mu \mathrm{M}$ phenylephrine (Figure 5-figure

118 supplement 1). As a consequence, combined application of CRF and $0.5 \mu \mathrm{M}$

119 phenylephrine enabled LTP with simultaneous synaptic stimulation-burst pairing

120 protocol, comparable to LTP induced in the presence of $1 \mu \mathrm{M}$ phenylephrine (Figure 121 5C,D).

122 Altogether, these data in VTA slices strongly suggest that CRF and NE promote

123 LTP-NMDA by differentially regulating $\mathrm{IP}_{3}-\mathrm{Ca}^{2+}$ signaling, i.e., via CRFR2-mediated

124 increase in $\mathrm{IP}_{3} \mathrm{R}$ sensitivity vs. $\alpha 1 \mathrm{AR}$-mediated generation of $\mathrm{IP}_{3}$, enabling them to act in

125 a synergistic fashion (Figure 6A,B). LTP magnitude was positively correlated with the

126 size of $\mathrm{I}_{\mathrm{K}(\mathrm{Ca})}$ facilitation during induction across neurons with different induction

127 conditions (Figure 6C), supporting the notion that $\mathrm{IP}_{3}$-dependent $\mathrm{Ca}^{2+}$ signal facilitation 128 drives LTP. 
130 CRF and NE synergize in the VTA to drive stress enhancement of cocaine place

\section{1 conditioning}

132 We next sought to explore if CRF and NE actions on NMDA plasticity in the VTA may

133 contribute to social stress-induced enhancement of cocaine CPP illustrated in Figure 1.

134 Low-dose cocaine $(5 \mathrm{mg} / \mathrm{kg})$ was used for conditioning in the following experiments to

135 avoid the ceiling effect observed with a higher dose (Fig. 1F). Although delivery of the

136 CRFR2 antagonist K41498 into the VTA prior to social defeat had small effect, stress-

137 enhanced cocaine conditioning was significantly suppressed by the $\alpha 1 \mathrm{AR}$ antagonist

138 prazosin and abolished by co-injection of K41498 and prazosin (Figure 7A-F). Thus

139 acute social defeat stress recruits a cooperative CRF and NE signaling mechanism acting

140 on CRFR2 and $\alpha 1 \mathrm{AR}$ in the VTA to promote cocaine conditioning.

141 Are CRF and NE actions in the VTA sufficient to enhance cocaine conditioning

142 in the absence of stress (Figure 7G)? While control rats injected with vehicle (PBS) into

143 the VTA developed inconsistent CPP, intra-VTA microinjection of CRF (1.5 pmol/0.3

$144 \mu \mathrm{L} /$ side) prior to cocaine conditioning enabled moderate CPP (Figure 7H,I,M). We

145 further found that administration of the $\alpha 1 \mathrm{AR}$ agonist phenylephrine (18 pmol/0.3

$146 \mu \mathrm{L} / \mathrm{side})$ lead to robust cocaine conditioning, although a lower dose $(6 \mathrm{pmol} / 0.3 \mu \mathrm{L} / \mathrm{side})$

147 had minimal effect (Figure 7J,K,M). Notably, combined application of CRF with low-

148 dose phenylephrine enabled large CPP comparable to that observed with high-dose

149 phenylephrine (Figure 7L,M). These data further support the idea that CRF and NE

150 synergize in the VTA to enhance cocaine conditioning. 


\section{Acute social defeat stress promotes Pavlovian cue-food conditioning and alleviates}

\section{3 temporal constraints on learning}

154 LTP-NMDA in DA neurons is induced in a burst-timing-dependent manner, where the

155 onset of glutamatergic input stimulation needs to precede postsynaptic burst, reflecting

156 the kinetics of mGluR-induced rise in $\mathrm{IP}_{3}$ to reach effective levels at the time of burst

157 (Harnett et al., 2009). This timing dependence of LTP might partially account for the 158 need of a delay between cue onset and reward delivery for the acquisition of cue-evoked

159 DA neuron bursting (Cohen et al., 2012; Kobayashi and Schultz, 2008) and appetitive

160 learning (Pavlov, 1927; Schwartz et al., 2002). If so, acute stress might alter the cue-

161 reward timing rule via $\mathrm{NE}$ action generating $\mathrm{IP}_{3}$, boosted by $\mathrm{CRF}$ effect on $\mathrm{IP}_{3} \mathrm{R}$

162 sensitivity. To test this idea, we used a Pavlovian conditioned approach paradigm and

163 varied the temporal relationship between the onset of cue (10 sec light at food magazine)

164 and delivery of reward (food pellet) during conditioning (Figure 8A and Figure 8-figure

165 supplement 1). While both handled controls and defeated rats developed a comparable

166 conditioned response to the food-paired cue (magazine entry, i.e., approach to the cue

167 light) after one conditioning session with $5 \mathrm{sec}$ cue-reward delay (Figure 8B,C and Figure

168 8-figure supplement 2), only defeated rats developed a cue response when the cue onset

169 and reward delivery were simultaneous (Figure 8D,E and Figure 8-figure supplement 2).

170 Neither group developed a conditioned response when the reward was delivered $5 \mathrm{sec}$

171 prior to cue onset (Figure 8F,G and Figure 8-figure supplement 2), suggesting that cue-

172 encoding neural activity needs to be active at the time of reward. Thus acute defeat stress

173 appeared to shift the cue-reward timing dependence, minimizing the requirement of delay

174 to drive effective conditioning (Figure $8 \mathrm{H}$ ). 


\section{DISCUSSION}

176 Multiple stress mediators, including glucocorticoids acting via a rapid non-genomic

177 pathway, interact, sometimes in an antagonistic fashion, to acutely regulate synaptic

178 plasticity and learning and memory processes (Joels et al., 2011; Maras and Baram, 2012;

179 McEwen, 2007). For example, corticosterone can promote or suppress the facilitatory

180 effect of NE, acting via $\beta$ adrenergic receptors ( $\beta \mathrm{ARs}$ ), on synaptic plasticity depending

181 on the timing of application in the hippocampus and amygdala (Akirav and Richter-

182 Levin, 2002; Pu et al., 2007, 2009), while a recent study reported a synergistic action of

183 corticosterone and CRF to impair hippocampal glutamatergic synapses and spatial

184 memory (Chen et al., 2016). The present study demonstrates that CRF and NE

185 synergistically augment $\mathrm{IP}_{3}-\mathrm{Ca}^{2+}$ signaling, via CRFR2-dependent increase in $\mathrm{IP}_{3}$

186 sensitivity and $\alpha 1 \mathrm{AR}$-dependent $\mathrm{IP}_{3}$ synthesis, respectively, driving enhanced plasticity

187 of NMDA transmission in VTA DA neurons. Our data further implicate a synergistic

188 action of CRFR2 and $\alpha 1 \mathrm{AR}$ signaling in acute social defeat stress-induced enhancement

189 of cocaine place conditioning. Thus this study identifies a potential molecular target on

190 which the two acute stress mediators act in concert to regulate a form of appetitive

191 learning.

192 While previous studies reporting CRF/NE-induced enhancement of AMPA

193 plasticity have mostly focused on regulation of neuronal excitability (Blank et al., 2002;

194 Liu et al., 2017) or postsynaptic AMPA receptors (Hu et al., 2007; Seol et al., 2007), our

195 study implicates $\mathrm{CRF} / \mathrm{NE}$ effects on a $\mathrm{Ca}^{2+}$-dependent induction process per se as the

196 metaplasticity mechanism for NMDA plasticity. Interestingly, NE acting on $\beta$ ARs has

197 been shown to enhance spike-timing-dependent plasticity in the hippocampus by 
198 relieving the constraints on the timing of pre- and postsynaptic spikes (Lin et al., 2003;

199 Seol et al., 2007) or on the number of postsynaptic spikes (Liu et al., 2017). The current

200 study suggests that $\mathrm{NE}$ acting on $\alpha 1 \mathrm{ARs}$ to generate $\mathrm{IP}_{3}$, together with $\mathrm{CRF}$ facilitating

201 this $\alpha 1 \mathrm{AR}$ effect, may remove the requirement of presynaptic stimulation preceding

202 postsynaptic bursting. Thus stress mediators appear to lower the "gate" for synaptic

203 plasticity at multiple levels in different brain areas.

204 Although our study has identified a critical role of CRFR2 in the VTA in

205 promoting NMDA plasticity and cocaine conditioning, it is known that DA neurons also

206 express CRFR1, which can control DA neuron physiology and reward/drug-driven

207 behaviors (Henckens et al., 2016). For example, while no significant effect of CRF (100-

$208300 \mathrm{nM}$ ) on NMDA transmission was observed in the current study, previous studies

209 have reported CRF effects on NMDA and AMPA transmission in VTA DA neurons,

210 involving multiple mechanisms via both CRFR1 and CRFR2 depending on the CRF

211 concentration used (Hahn et al., 2009; Ungless et al., 2003; Williams et al., 2014). It

212 remains to be determined how multiple CRF effects on glutamatergic transmission reflect

213 heterogeneity of DA neurons in the VTA, especially given differential effects of

214 appetitive vs. aversive/stressful stimuli on these neurons (Holly and Miczek, 2016;

215 Lammel et al., 2011; Morales and Margolis, 2017; Polter and Kauer, 2014). Regardless,

216 these CRFR1/CRFR2-dependent effects on glutamatergic excitation, together with

217 CRF/NE effects on DA neuron firing (Paladini et al., 2001; Wanat et al., 2008), may

218 contribute to the acute stress-induced enhancement of the expression of drug-seeking

219 behavior observed in vivo (Holly et al., 2016; Mantsch et al., 2016; Wang et al., 2007). It

220 should be noted that CRF and NE actions in other limbic structures also contribute to 
221 different aspects of reward-driven behavior (Henckens et al., 2016; Otis et al., 2015;

222 Smith and Aston-Jones, 2008). Despite the engagement of multiple brain circuits in

223 response to acute stress-induced CRF/NE actions, our data implicate VTA DA neuron

224 plasticity as the critical substrate for enhancement of appetitive cue learning.

225 The VTA receives inputs from several CRF-rich regions including the bed

226 nucleus of the stria terminalis, central amygdala, and paraventricular hypothalamus, and

227 paraventricular hypothalamus (Rodaros et al., 2007), while major sources of NE to the

228 VTA are the locus coeruleus and A1, A2, and A5 noradrenergic cell groups that exhibit

229 distinct topography of innervation to VTA subareas (Mejias-Aponte et al., 2009). Indeed,

230 many of these brain areas are activated by social defeat stress (Martinez et al., 1998).

231 Different types of stress may differentially recruit CRF and NE sources to the VTA, thus

232 creating different levels of CRF and NE to regulate their synergistic interaction.

233 It is well known that brief stressful experience could lead to persistent changes in

234 brain function depending on the intensity or controllability of the stressor (Musazzi et al.,

235 2017). Indeed, a number of studies have shown persistent changes in VTA synapses

236 lasting $>1$ day following single or repeated stress exposure, which are frequently linked

237 to intensification and/or reinstatement of drug-seeking behavior (Polter and Kauer, 2014).

238 Our previous study has shown that repeated (5 day), but not single, social defeat stress

239 promotes the NMDA plasticity mechanism 1-10 days later, which is associated with

240 enhanced cocaine CPP (Stelly et al., 2016). Enhancement of plasticity and CPP both

241 require glucocorticoid action during stress exposure, likely through glucocorticoid

242 receptors mediating long-lasting changes in gene expression. Although blockade of CRF

243 and NE signaling in the VTA completely suppressed acute stress effect on CPP in the 
244 current study, it may be possible that rapid non-genomic glucocorticoid effects may play

245 a permissive role, as has been demonstrated for the effects of CRF and/or NE on synaptic

246 function and memory processes in the hippocampus and amygdala (Chen et al., 2016;

247 Roozendaal et al., 2008).

248 Interestingly, acute stress (inescapable electric shock or swim stress) has been

249 shown to enhance Pavlovian eyeblink conditioning (Shors, 2001; Shors et al., 1992),

250 which may be driven by a form of synaptic plasticity in the cerebellum that is dependent

251 on an $\mathrm{IP}_{3}-\mathrm{Ca}^{2+}$ signaling mechanism similar to NMDA plasticity in DA neurons (Wang et

252 al., 2000). This facilitatory effect on eyeblink conditioning can be observed 30 min to 24

$253 \mathrm{hr}$ after stress exposure, while the effect on cocaine CPP was observed $30 \mathrm{~min}$, but not

$2541.5 \mathrm{hr}$ (current study) or $24 \mathrm{hr}$ (Stelly et al., 2016), following a single episode of defeat

255 stress. The role of different stress mediators underlying the persistence of single stress

256 exposure on eyeblink conditioning has not been explored, although the effects of CRF

257 and NE on cerebellar synaptic plasticity have been reported (Carey and Regehr, 2009;

258 Schmolesky et al., 2007). It should also be noted that a single exposure to inescapable

259 footshock or restraint stress has been reported to promote CPP acquisition for days

260 (Pacchioni et al., 2002; Will et al., 1998).

261 In the present study, the facilitatory effect of acute social defeat stress on

262 Pavlovian cue learning was observed not only with cocaine (i.e., drug reward) but also

263 when food reward was used as an unconditioned stimulus (US) for conditioning. Indeed,

264 a recent human study has reported that brief exposure to cold stress 2 min prior to

265 Pavlovian conditioning sessions using monetary rewards promoted cue-evoked activity in

266 the ventral striatum (Lewis et al., 2014). It is well established that the cue needs to be 
267 presented prior to the US for different types of Pavlovian conditioning (Pavlov, 1927;

268 Schwartz et al., 2002). Intriguingly, stressed rats acquired a cue response (i.e., approach

269 to the cue light) even when the cue and US (food pellet) were presented simultaneously,

270 in apparent violation of a canonical principle of Pavlovian conditioning. Although

271 speculative, concerted $\mathrm{CRF}$ and NE actions on $\mathrm{IP}_{3}$ signaling in VTA DA neurons might

272 mitigate the requirement of the delay from cue onset to reward delivery, during which

273 cue-evoked glutamatergic input activating mGluRs is hypothesized to cause $\mathrm{IP}_{3}$ rise at the

274 time of reward-evoked bursting to effectively drive NMDA potentiation (Harnett et al.,

275 2009). By enabling simultaneous cue-reward conditioning, daily stressful experience may

276 lead to spurious learning of reward-associated cues with no predictive value or redundant

277 cues presented at the same time with already learned cues (e.g., money) (Holland, 1984),

278 thereby driving increased addiction liability to drug and non-drug rewards. 


\section{$281 \quad$ Animals}

282 Sprague-Dawley rats (Harlan Laboratories, Houston, Texas) were housed in pairs on a

283 12-hr light/dark cycle with food and water available ad libitum. All procedures were

284 approved by the University of Texas Institutional Animal Care and Use Committee.

\section{Brain slice electrophysiology}

287 Midbrain slices were prepared and recordings were made in the lateral VTA located 50-

$288150 \mathrm{~mm}$ from the medial border of the medial terminal nucleus of the accessory optic

289 tract, as in our previous studies (Stelly et al., 2016; Whitaker et al., 2013). Tyrosine

290 hydroxylase-positive neurons in this area (i.e., lateral part of the parabrachial pigmented

291 nucleus) largely project to the ventrolateral striatum (Ikemoto, 2007) and show little

292 VGluT2 coexpression (Trudeau et al., 2014). Internal solution contained (in mM): 115 K-

293 methylsulfate, $20 \mathrm{KCl}, 1.5 \mathrm{MgCl}_{2}, 10 \mathrm{HEPES}, 0.025$ EGTA, $2 \mathrm{Mg}$-ATP, $0.2 \mathrm{Na}_{2}$-GTP,

294 and $10 \mathrm{Na}_{2}$-phosphocreatine $(\mathrm{pH} \sim 7.25, \sim 285 \mathrm{mOsm} / \mathrm{kg})$. Putative dopamine neurons in

295 the lateral VTA were identified by spontaneous firing of broad APs $(>1.2 \mathrm{~ms})$ at $1-5 \mathrm{~Hz}$

296 in cell-attached configuration and large $\mathrm{I}_{\mathrm{h}}$ currents $(>200$ pA; evoked by a $1.5 \mathrm{~s}$

297 hyperpolarizing step of $50 \mathrm{mV}$ ) in whole-cell configuration (Ford et al., 2006; Lammel et

298 al., 2008; Margolis et al., 2008). Cells were voltage-clamped at $-62 \mathrm{mV}$ (corrected for -7

$299 \mathrm{mV}$ liquid junction potential). A $2 \mathrm{~ms}$ depolarizing pulse of $55 \mathrm{mV}$ was used to elicit an

300 unclamped AP. For bursts, 5 APs were evoked at $20 \mathrm{~Hz}$. The time integral of the outward

301 tail current, termed $\mathrm{I}_{\mathrm{K}(\mathrm{Ca})}$ (calculated after removing the $20 \mathrm{~ms}$ window following each

302 depolarizing pulse; expressed in $\mathrm{pC}$ ), was used as a readout of AP-evoked $\mathrm{Ca}^{2+}$ 
303 transients, as it is eliminated by TTX and also by apamin, a blocker of $\mathrm{Ca}^{2+}$-activated SK

304 channels (Cui et al., 2007).

305

\section{UV Photolysis}

307 Cells were loaded with caged $\mathrm{IP}_{3}(1-10 \mu \mathrm{M})$ through the recording pipette. UV light (100

308 ms) was applied using the excitation light from the xenon arc lamp of the Olympus Disk

309 Spinning Unit imaging system. The light was focused through a $60 \times$ objective onto a

$310 \sim 350 \mu \mathrm{m}$ area surrounding the recorded neuron. Photolysis of caged compounds is

311 proportional to the UV light intensity, which was adjusted with neutral density filters and

312 measured at the focal plane of the objective (in $\mathrm{mW}$ ). The applied $\mathrm{IP}_{3}$ concentration is

313 expressed in $\mu \mathrm{M} \cdot \mathrm{mW}$.

\section{LTP experiments}

316 Synaptic stimuli were delivered with a bipolar tungsten electrode placed $\sim 200 \mu \mathrm{m}$ rostral

317 to the recorded neuron. To isolate NMDA EPSCs, recordings were performed in DNQX

$318(10 \mu \mathrm{M})$, picrotoxin $(100 \mu \mathrm{M})$, CGP54626 $(50 \mathrm{nM})$, and sulpiride (100 nM) to block

319 AMPA/kainate, $\mathrm{GABA}_{\mathrm{A}}, \mathrm{GABA}_{\mathrm{B}}$, and $\mathrm{D}_{2}$ dopamine receptors, and in glycine $(20 \mu \mathrm{M})$

320 and low $\mathrm{Mg}^{2+}(0.1 \mathrm{mM})$ to enhance NMDA receptor activation. NMDA EPSCs were

321 monitored every $20 \mathrm{~s}$. The LTP induction protocol consisted of photolytic application of

$322 \mathrm{IP}_{3}(10 \mu \mathrm{M} \cdot \mathrm{mW})$ for $100 \mathrm{~ms}$ prior to the simultaneous delivery of afferent stimulation (20

323 stimuli at $50 \mathrm{~Hz}$ ) and postsynaptic burst (5 APs at $20 \mathrm{~Hz}$ ), repeated 10 times every $20 \mathrm{~s}$.

324 LTP magnitude was determined by comparing the average EPSC amplitude 30-40 min

325 post-induction with the average EPSC amplitude pre-induction (each from a 10 min 
326 window).

327

328 Resident-Intruder Social Defeat Paradigm

329 Twelve week-old male resident rats were vasectomized and pair-housed with 6 week-old

330 females. Residents (used for $\sim 8-10$ months) were screened for aggression (biting or

331 pinning within $1 \mathrm{~min}$ ) by introducing a male intruder to the home cage. Intruders and

332 controls were young males (4-5 weeks old at the beginning) housed in pairs. For defeat

333 sessions, intruders were introduced to residents' home cages after removing females.

334 Following $\sim 5$ min of direct contact, a perforated Plexiglass barrier was inserted for $\sim 25$

335 min to allow sensory contact, as in our previous study (Stelly et al., 2016). The barrier

336 was removed for a brief period ( $<1 \mathrm{~min})$ in certain cases to encourage residents'

337 threatening behavior. Handled controls were placed in novel cages for $30 \mathrm{~min}$. Intruders

338 and controls were housed separately.

340 Cocaine Place Conditioning

341 CPP boxes (Med Associates) consisting of two distinct compartments separated by a

342 small middle chamber were used for conditioning. One compartment had a mesh floor

343 with white walls, while the other had a grid floor with black walls. A discrete cue

344 (painted ceramic weight) was placed in the rear corner of each compartment (black one in

345 the white wall side, white one in the black wall side) for further differentiation. Rats were

346 first subjected to a pretest, in which they explored the entire CPP box for $15 \mathrm{~min}$. The

347 percentage of time spent in each compartment was determined after excluding the time

348 spent in the middle chamber. Rats with initial side preference $>60 \%$ were excluded. The 
349 following day, rats were given a saline injection in the morning and confined to one

350 compartment, then in the afternoon given cocaine (5 or $10 \mathrm{mg} / \mathrm{kg}$, i.p.) and confined to

351 the other compartment (10 min each). Compartment assignment was counterbalanced

352 such that animals had, on average, $\sim 50 \%$ initial preference for the cocaine-paired side. A

35315 min posttest was performed 1 day after conditioning. The CPP score was determined

354 by subtracting the preference for the cocaine-paired side during pretest from that during

355 posttest. The experimenter performing CPP experiments was blind to animal treatments.

357 Intra-VTA microinjections

358 Rats (7-10 weeks old) were anesthetized with a mixture of ketamine and xylazine (90

$359 \mathrm{mg} / \mathrm{kg}$ and $10 \mathrm{mg} / \mathrm{kg}$, i.p.) and implanted with bilateral chronic guide cannulas (22 gauge;

360 Plastics One), with dummy cannulas (32 gauge) inside, aimed at $1 \mathrm{~mm}$ above the VTA

361 (anteroposterior, -5.3; mediolateral, +2.2; dorsoventral, $-7.5 ; 10^{\circ}$ angle). The guide

362 cannulas were fixed to the skull with stainless steal screws and dental cement. After the

363 surgery, rats remained singly housed for 7 days before being subjected to conditioning

364 experiments.

365 Intra-VTA microinjections were made via injection cannulas (28 gauge; Plastics

366 One) that extended $1 \mathrm{~mm}$ beyond the tip of the guide cannulas. Injection cannulas were

367 connected to $1 \mu \mathrm{L}$ Hamilton syringes mounted on a microdrive pump (Harvard

368 apparatus). Rats received bilateral infusions $(0.3 \mu \mathrm{L} /$ side, $0.15 \mu \mathrm{L} / \mathrm{min})$ of different

369 pharmacological agents in certain conditioning experiments. The injection cannulas were

$370 \quad$ left in place for $60 \mathrm{~s}$ after infusion.

371 At the end of conditioning experiments, rats were anesthetized with a mixture of 
372 ketamine and xylazine (90 mg/kg and $10 \mathrm{mg} / \mathrm{kg}$, i.p.) and transcardially perfused with $4 \%$

373 paraformaldehyde. Brains were then carefully removed and stored in 4\%

374 paraformaldehyde. Coronal sections $(100 \mu \mathrm{m})$ were cut using a vibratome and stained

375 with cresyl violet for histological verification of injections sites (Figure 7-figure

376 supplement 1). Data from rats with injection sites outside the VTA were excluded from

377 the analysis.

379 Pavlovian Conditioned Approach

380 Conditioning was performed in modular test chambers (Med Associates) equipped with a

381 food pellet receptacle at the center of one wall. Illuminating light at the rear of receptacle

382 was used as a cue during conditioning (house light was turned off). Head entry was

383 detected with infrared photobeam positioned across the receptacle. All sessions were

384 performed on a $60 \mathrm{sec}$ variable inter-trial interval schedule (range $40-80 \mathrm{sec}$ ). Each

385 session was preceded by a $5 \mathrm{~min}$ acclimation period during which rats stayed in the

386 chamber with no food pellet delivery or cue light illumination. Rats first underwent 4-7

387 days of magazine training sessions in which rats received 30 banana-flavored food pellets

388 (45 mg; Bio-Serv) with no light illumination at the receptacle and learn to rapidly (within

$389 \sim 1 \mathrm{sec}$ ) respond to the food drop sound (Figure 8-figure supplement 3). To minimize

390 unconditioned response to the receptacle light, rats received 4-7 days of habituation

391 sessions where rats were exposed to $10 \mathrm{sec}$ illumination of receptacle light with no food

392 delivery (15-30 trials per day; alternated with several days of magazine training

393 sessions). The final habituation session (15 trials) was used as a pretest to assess the

394 response to the cue light before conditioning. On the day following this pretest, rats 
395 underwent 30 trial conditioning sessions, in which the food pellet was delivered either at

396 the onset of the $10 \mathrm{sec}$ light cue, $5 \mathrm{sec}$ after the cue onset (i.e., at the middle of $10 \mathrm{sec}$

397 light cue), or $5 \mathrm{sec}$ before the cue onset. Posttest (15 trials, cue light with no food) was

398 performed 1 day after conditioning. Responses were measured with the proportion of

399 trials in which head entry was detected in each second (labeled $\mathrm{P}(\mathrm{head} \mathrm{in}) / \mathrm{sec})$. The mean

400 value during the $10 \mathrm{sec}$ baseline period before cue onset was subtracted in each rat to

401 assess the cue light response. Rats displaying significant non-habituated cue response

402 during the pretest (mean $\mathrm{P}($ head in)/sec $>0.1$ above baseline level during the $20 \mathrm{sec}$

403 period from cue onset, averaged over 15 trials) were excluded from analysis. The

404 conditioning score was determined by subtracting the mean $\mathrm{P}($ head in)/sec above baseline

405 level in the pretest from that in the posttest (expressed in \%).

\section{Drugs}

408 DNQX, picrotoxin, CGP55845, sulpiride, CRF and K41498 were obtained from Tocris

409 Biosciences. Caged $\mathrm{IP}_{3}$ was a generous gift from Dr. Kamran Khodakhah (Albert

410 Einstein College of Medicine). All other chemicals were from Sigma-RBI.

\section{Data Analysis}

414 Data are expressed as mean \pm SEM. Statistical significance was determined by Student's $\mathrm{t}$

415 test or ANOVA followed by Bonferroni or Dunnett's post hoc test. The difference was

416 considered significant at $\mathrm{p}<0.05$. 


\section{ACKNOWLEDGEMENTS}

419 We thank Dr. Kamran Khodakhah for the generous gift of caged $\mathrm{IP}_{3}$ made in his lab at

420 Albert Einstein College of Medicine. We also thank Dr. Claire Stelly for comments on

421 this manuscript.

\section{COMPETING INTERESTS}

424 All authors declare no biomedical financial interests or potential conflict of interest. 


\section{REFERENCES}

428 Akirav, I., and Richter-Levin, G. (2002). Mechanisms of amygdala modulation of

429 hippocampal plasticity. J Neurosci 22, 9912-9921.

430 Bernier, B.E., Whitaker, L.R., and Morikawa, H. (2011). Previous ethanol experience

431 enhances synaptic plasticity of NMDA receptors in the ventral tegmental area. J Neurosci

$432 \quad 31,5205-5212$.

433 Blank, T., Nijholt, I., Eckart, K., and Spiess, J. (2002). Priming of long-term potentiation

434 in mouse hippocampus by corticotropin-releasing factor and acute stress: implications for 435 hippocampus-dependent learning. J Neurosci 22, 3788-3794.

436 Burke, A.R., Watt, M.J., and Forster, G.L. (2011). Adolescent social defeat increases

437 adult amphetamine conditioned place preference and alters D2 dopamine receptor

438 expression. Neuroscience 197, 269-279.

439 Carey, M.R., and Regehr, W.G. (2009). Noradrenergic control of associative synaptic

440 plasticity by selective modulation of instructive signals. Neuron 62, 112-122.

441 Chattarji, S., Tomar, A., Suvrathan, A., Ghosh, S., and Rahman, M.M. (2015).

442 Neighborhood matters: divergent patterns of stress-induced plasticity across the brain.

$443 \quad$ Nat Neurosci 18, 1364-1375.

444 Chen, Y., Molet, J., Lauterborn, J.C., Trieu, B.H., Bolton, J.L., Patterson, K.P., Gall,

445 C.M., Lynch, G., and Baram, T.Z. (2016). Converging, Synergistic Actions of Multiple 
446 Stress Hormones Mediate Enduring Memory Impairments after Acute Simultaneous

447 Stresses. J Neurosci 36, 11295-11307.

448 Chuang, J.C., Perello, M., Sakata, I., Osborne-Lawrence, S., Savitt, J.M., Lutter, M., and

449 Zigman, J.M. (2011). Ghrelin mediates stress-induced food-reward behavior in mice. The

450 Journal of clinical investigation 121, 2684-2692.

451 Cohen, J.Y., Haesler, S., Vong, L., Lowell, B.B., and Uchida, N. (2012). Neuron-type-

452 specific signals for reward and punishment in the ventral tegmental area. Nature 482, 85-

45388.

454 Covey, D.P., Roitman, M.F., and Garris, P.A. (2014). Illicit dopamine transients:

455 reconciling actions of abused drugs. Trends Neurosci 37, 200-210.

456 Cui, G., Bernier, B.E., Harnett, M.T., and Morikawa, H. (2007). Differential regulation of

457 action potential- and metabotropic glutamate receptor-induced $\mathrm{Ca} 2+$ signals by inositol

458 1,4,5-trisphosphate in dopaminergic neurons. J Neurosci 27, 4776-4785.

459 Cui, G., Okamoto, T., and Morikawa, H. (2004). Spontaneous opening of T-type Ca2+

460 channels contributes to the irregular firing of dopamine neurons in neonatal rats. J

$461 \quad$ Neurosci 24, 11079-11087.

462 Ford, C.P., Mark, G.P., and Williams, J.T. (2006). Properties and opioid inhibition of

463 mesolimbic dopamine neurons vary according to target location. J Neurosci 26, 2788-

4642797. 
465 Hahn, J., Hopf, F.W., and Bonci, A. (2009). Chronic cocaine enhances corticotropin-

466 releasing factor-dependent potentiation of excitatory transmission in ventral tegmental

467 area dopamine neurons. J Neurosci 29, 6535-6544.

468 Harnett, M.T., Bernier, B.E., Ahn, K.C., and Morikawa, H. (2009). Burst-timing-

469 dependent plasticity of NMDA receptor-mediated transmission in midbrain dopamine

470 neurons. Neuron 62, 826-838.

471 Henckens, M.J., Deussing, J.M., and Chen, A. (2016). Region-specific roles of the

472 corticotropin-releasing factor-urocortin system in stress. Nat Rev Neurosci 17, 636-651.

473 Holland, P.C. (1984). Unblocking in Pavlovian appetitive conditioning. Journal of

474 experimental psychology Animal behavior processes 10, 476-497.

475 Holly, E.N., Boyson, C.O., Montagud-Romero, S., Stein, D.J., Gobrogge, K.L., DeBold,

476 J.F., and Miczek, K.A. (2016). Episodic Social Stress-Escalated Cocaine Self-

477 Administration: Role of Phasic and Tonic Corticotropin Releasing Factor in the Anterior

478 and Posterior Ventral Tegmental Area. J Neurosci 36, 4093-4105.

479 Holly, E.N., and Miczek, K.A. (2016). Ventral tegmental area dopamine revisited: effects

480 of acute and repeated stress. Psychopharmacology (Berl) 233, 163-186.

481 Hu, H., Real, E., Takamiya, K., Kang, M.G., Ledoux, J., Huganir, R.L., and Malinow, R.

482 (2007). Emotion enhances learning via norepinephrine regulation of AMPA-receptor

483 trafficking. Cell 131, 160-173. 
484 Ikemoto, S. (2007). Dopamine reward circuitry: two projection systems from the ventral

485 midbrain to the nucleus accumbens-olfactory tubercle complex. Brain Res Rev 56, 27-78.

486 Joels, M., Fernandez, G., and Roozendaal, B. (2011). Stress and emotional memory: a

487 matter of timing. Trends in cognitive sciences 15, 280-288.

488 Keiflin, R., and Janak, P.H. (2015). Dopamine Prediction Errors in Reward Learning and

489 Addiction: From Theory to Neural Circuitry. Neuron 88, 247-263.

490 Kim, E.J., Pellman, B., and Kim, J.J. (2015). Stress effects on the hippocampus: a critical

491 review. Learn Mem 22, 411-416.

492 Kobayashi, S., and Schultz, W. (2008). Influence of reward delays on responses of

493 dopamine neurons. J Neurosci 28, 7837-7846.

494 Koolhaas, J.M., Bartolomucci, A., Buwalda, B., de Boer, S.F., Flugge, G., Korte, S.M.,

495 Meerlo, P., Murison, R., Olivier, B., Palanza, P., et al. (2011). Stress revisited: a critical

496 evaluation of the stress concept. Neurosci Biobehav Rev 35, 1291-1301.

497 Kreibich, A.S., Briand, L., Cleck, J.N., Ecke, L., Rice, K.C., and Blendy, J.A. (2009).

498 Stress-induced potentiation of cocaine reward: a role for CRF R1 and CREB.

499 Neuropsychopharmacology 34, 2609-2617.

500 Lammel, S., Hetzel, A., Hackel, O., Jones, I., Liss, B., and Roeper, J. (2008). Unique

501 properties of mesoprefrontal neurons within a dual mesocorticolimbic dopamine system.

502 Neuron 57, 760-773. 
503 Lammel, S., Ion, D.I., Roeper, J., and Malenka, R.C. (2011). Projection-specific

504 modulation of dopamine neuron synapses by aversive and rewarding stimuli. Neuron 70,

$505 \quad 855-862$.

506 Lewis, A.H., Porcelli, A.J., and Delgado, M.R. (2014). The effects of acute stress

507 exposure on striatal activity during Pavlovian conditioning with monetary gains and

508 losses. Front Behav Neurosci 8, 179.

509 Lin, Y.W., Min, M.Y., Chiu, T.H., and Yang, H.W. (2003). Enhancement of associative

510 long-term potentiation by activation of beta-adrenergic receptors at CA1 synapses in rat

511 hippocampal slices. J Neurosci 23, 4173-4181.

512 Liu, Y., Cui, L., Schwarz, M.K., Dong, Y., and Schluter, O.M. (2017). Adrenergic Gate

513 Release for Spike Timing-Dependent Synaptic Potentiation. Neuron 93, 394-408.

514 Mantsch, J.R., Baker, D.A., Funk, D., Le, A.D., and Shaham, Y. (2016). Stress-Induced

515 Reinstatement of Drug Seeking: 20 Years of Progress. Neuropsychopharmacology 41,

$516 \quad 335-356$

517 Maras, P.M., and Baram, T.Z. (2012). Sculpting the hippocampus from within: stress,

518 spines, and CRH. Trends in neurosciences 35, 315-324.

519 Margolis, E.B., Mitchell, J.M., Ishikawa, J., Hjelmstad, G.O., and Fields, H.L. (2008).

520 Midbrain dopamine neurons: projection target determines action potential duration and

521 dopamine $\mathrm{D}(2)$ receptor inhibition. J Neurosci 28, 8908-8913. 
522 Martinez, M., Phillips, P.J., and Herbert, J. (1998). Adaptation in patterns of c-fos

523 expression in the brain associated with exposure to either single or repeated social stress

524 in male rats. Eur J Neurosci 10, 20-33.

525 McEwen, B.S. (2007). Physiology and Neurobiology of Stress and Adaptation: Central

526 Role of the Brain. Physiological Reviews 87, 873-904.

527 Mejias-Aponte, C.A., Drouin, C., and Aston-Jones, G. (2009). Adrenergic and

528 noradrenergic innervation of the midbrain ventral tegmental area and retrorubral field:

529 prominent inputs from medullary homeostatic centers. J Neurosci 29, 3613-3626.

530 Morales, M., and Margolis, E.B. (2017). Ventral tegmental area: cellular heterogeneity,

531 connectivity and behaviour. Nat Rev Neurosci 18, 73-85.

532 Musazzi, L., Tornese, P., Sala, N., and Popoli, M. (2017). Acute or Chronic? A Stressful

533 Question. Trends in neurosciences.

534 Otis, J.M., Werner, C.T., and Mueller, D. (2015). Noradrenergic regulation of fear and

535 drug-associated memory reconsolidation. Neuropsychopharmacology 40, 793-803.

536 Overton, P.G., and Clark, D. (1997). Burst firing in midbrain dopaminergic neurons.

537 Brain Res Brain Res Rev 25, 312-334.

538 Pacchioni, A.M., Gioino, G., Assis, A., and Cancela, L.M. (2002). A single exposure to

539 restraint stress induces behavioral and neurochemical sensitization to stimulating effects

540 of amphetamine: involvement of NMDA receptors. Ann N Y Acad Sci 965, 233-246. 
541 Paladini, C.A., Fiorillo, C.D., Morikawa, H., and Williams, J.T. (2001). Amphetamine

542 selectively blocks inhibitory glutamate transmission in dopamine neurons. Nat Neurosci

$543 \quad 4,275-281$.

544 Paladini, C.A., and Roeper, J. (2014). Generating bursts (and pauses) in the dopamine

545 midbrain neurons. Neuroscience 282, 109-121.

546 Pavlov, I.P. (1927). Conditioned reflexes (London, UK: Oxford University Press).

547 Polter, A.M., and Kauer, J.A. (2014). Stress and VTA synapses: implications for

548 addiction and depression. Eur J Neurosci 39, 1179-1188.

549 Pu, Z., Krugers, H.J., and Joels, M. (2007). Corticosterone time-dependently modulates

550 beta-adrenergic effects on long-term potentiation in the hippocampal dentate gyrus. Learn

551 Mem 14, 359-367.

552 Pu, Z., Krugers, H.J., and Joels, M. (2009). Beta-adrenergic facilitation of synaptic

553 plasticity in the rat basolateral amygdala in vitro is gradually reversed by corticosterone.

554 Learn Mem 16, 155-160.

555 Riegel, A.C., and Williams, J.T. (2008). CRF facilitates calcium release from

556 intracellular stores in midbrain dopamine neurons. Neuron 57, 559-570.

557 Rodaros, D., Caruana, D.A., Amir, S., and Stewart, J. (2007). Corticotropin-releasing

558 factor projections from limbic forebrain and paraventricular nucleus of the hypothalamus

559 to the region of the ventral tegmental area. Neuroscience $150,8-13$. 
560 Rodrigues, S.M., LeDoux, J.E., and Sapolsky, R.M. (2009). The influence of stress

561 hormones on fear circuitry. Annu Rev Neurosci 32, 289-313.

562 Roozendaal, B., Schelling, G., and McGaugh, J.L. (2008). Corticotropin-releasing factor

563 in the basolateral amygdala enhances memory consolidation via an interaction with the

564 beta-adrenoceptor-cAMP pathway: dependence on glucocorticoid receptor activation. J

565 Neurosci 28, 6642-6651.

566 Schmolesky, M.T., De Ruiter, M.M., De Zeeuw, C.I., and Hansel, C. (2007). The

567 neuropeptide corticotropin-releasing factor regulates excitatory transmission and

568 plasticity at the climbing fibre-Purkinje cell synapse. Eur J Neurosci 25, 1460-1466.

569 Schultz, W. (1998). Predictive reward signal of dopamine neurons. J Neurophysiol 80, 1-

57027.

571 Schultz, W. (2015). Neuronal Reward and Decision Signals: From Theories to Data.

572 Physiological reviews 95, 853-951.

573 Schwartz, B., Wasserman, E.A., and Robbins, S.J. (2002). Psychology of learning and

574 behavior, 5th edn (New York, NY: W. W. Norton \& Company).

575 Seol, G.H., Ziburkus, J., Huang, S., Song, L., Kim, I.T., Takamiya, K., Huganir, R.L.,

576 Lee, H.K., and Kirkwood, A. (2007). Neuromodulators control the polarity of spike-

577 timing-dependent synaptic plasticity. Neuron 55, 919-929.

578 Shors, T.J. (2001). Acute stress rapidly and persistently enhances memory formation in

579 the male rat. Neurobiology of learning and memory 75, 10-29. 
580 Shors, T.J., Weiss, C., and Thompson, R.F. (1992). Stress-induced facilitation of classical

581 conditioning. Science 257, 537-539.

582 Sinha, R. (2008). Chronic stress, drug use, and vulnerability to addiction. Ann N Y Acad

583 Sci 1141, 105-130.

584 Smith, J.S., Schindler, A.G., Martinelli, E., Gustin, R.M., Bruchas, M.R., and Chavkin,

585 C. (2012). Stress-induced activation of the dynorphin/kappa-opioid receptor system in the

586 amygdala potentiates nicotine conditioned place preference. J Neurosci 32, 1488-1495.

587 Smith, R.J., and Aston-Jones, G. (2008). Noradrenergic transmission in the extended

588 amygdala: role in increased drug-seeking and relapse during protracted drug abstinence.

589 Brain Struct Funct 213, 43-61.

590 Stauffer, W.R., Lak, A., Yang, A., Borel, M., Paulsen, O., Boyden, E.S., and Schultz, W.

591 (2016). Dopamine Neuron-Specific Optogenetic Stimulation in Rhesus Macaques. Cell

$592166,1564-1571$ e1566.

593 Stelly, C.E., Pomrenze, M.B., Cook, J.B., and Morikawa, H. (2016). Repeated social

594 defeat stress enhances glutamatergic synaptic plasticity in the VTA and cocaine place

595 conditioning. Elife 5.

596 Taylor, C.W., and Laude, A.J. (2002). IP3 receptors and their regulation by calmodulin

597 and cytosolic Ca2+. Cell Calcium 32, 321-334. 
598 Trudeau, L.E., Hnasko, T.S., Wallen-Mackenzie, A., Morales, M., Rayport, S., and

599 Sulzer, D. (2014). The multilingual nature of dopamine neurons. Prog Brain Res 211,

600 141-164.

601 Ungless, M.A., Singh, V., Crowder, T.L., Yaka, R., Ron, D., and Bonci, A. (2003).

602 Corticotropin-Releasing Factor Requires CRF Binding Protein to Potentiate NMDA

603 Receptors via CRF Receptor 2 in Dopamine Neurons. Neuron 39, 401-407.

604 Wagner, L.E., 2nd, Joseph, S.K., and Yule, D.I. (2008). Regulation of single inositol

605 1,4,5-trisphosphate receptor channel activity by protein kinase A phosphorylation. J

606 Physiol 586, 3577-3596.

607 Wanat, M.J., Hopf, F.W., Stuber, G.D., Phillips, P.E., and Bonci, A. (2008).

608 Corticotropin-releasing factor increases mouse ventral tegmental area dopamine neuron

609 firing through a protein kinase C-dependent enhancement of Ih. J Physiol 586, 2157-

6102170.

611 Wang, B., You, Z.B., Rice, K.C., and Wise, R.A. (2007). Stress-induced relapse to

612 cocaine seeking: roles for the $\mathrm{CRF}(2)$ receptor and CRF-binding protein in the ventral

613 tegmental area of the rat. Psychopharmacology (Berl) 193, 283-294.

614 Wang, L.P., Li, F., Wang, D., Xie, K., Wang, D., Shen, X., and Tsien, J.Z. (2011).

615 NMDA receptors in dopaminergic neurons are crucial for habit learning. Neuron 72,

$616 \quad 1055-1066$.

617 Wang, S.S., Denk, W., and Hausser, M. (2000). Coincidence detection in single dendritic

618 spines mediated by calcium release. Nat Neurosci 3, 1266-1273. 
619 Whitaker, L.R., Degoulet, M., and Morikawa, H. (2013). Social deprivation enhances

620 VTA synaptic plasticity and drug-induced contextual learning. Neuron 77, 335-345.

621 Will, M.J., Watkins, L.R., and Maier, S.F. (1998). Uncontrollable stress potentiates

622 morphine's rewarding properties. Pharmacol Biochem Behav 60, 655-664.

623 Williams, C.L., Buchta, W.C., and Riegel, A.C. (2014). CRF-R2 and the heterosynaptic

624 regulation of VTA glutamate during reinstatement of cocaine seeking. J Neurosci 34,

$625 \quad 10402-10414$.

626 Zweifel, L.S., Argilli, E., Bonci, A., and Palmiter, R.D. (2008). Role of NMDA receptors

627 in dopamine neurons for plasticity and addictive behaviors. Neuron 59, 486-496.

628 Zweifel, L.S., Parker, J.G., Lobb, C.J., Rainwater, A., Wall, V.Z., Fadok, J.P., Darvas,

629 M., Kim, M.J., Mizumori, S.J., Paladini, C.A., et al. (2009). Disruption of NMDAR-

630 dependent burst firing by dopamine neurons provides selective assessment of phasic

631 dopamine-dependent behavior. Proc Natl Acad Sci U S A 106, 7281-7288.

632 


\section{FGIRUES}

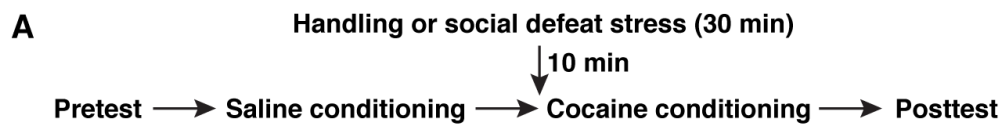
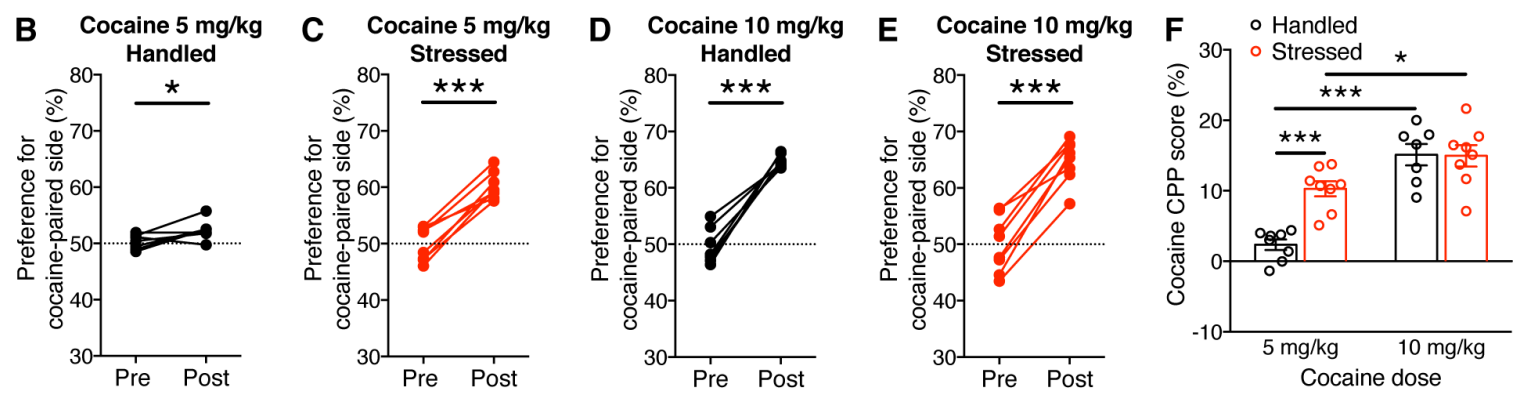

G

Handling or social defeat stress $(30 \mathrm{~min})$

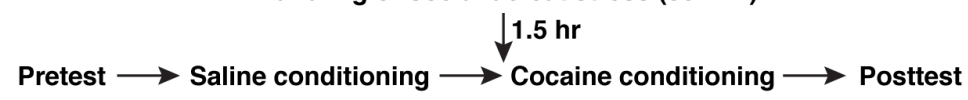

634

H $\begin{gathered}\text { Cocaine } 5 \mathrm{mg} / \mathrm{kg} \\ \text { Handled }\end{gathered}$
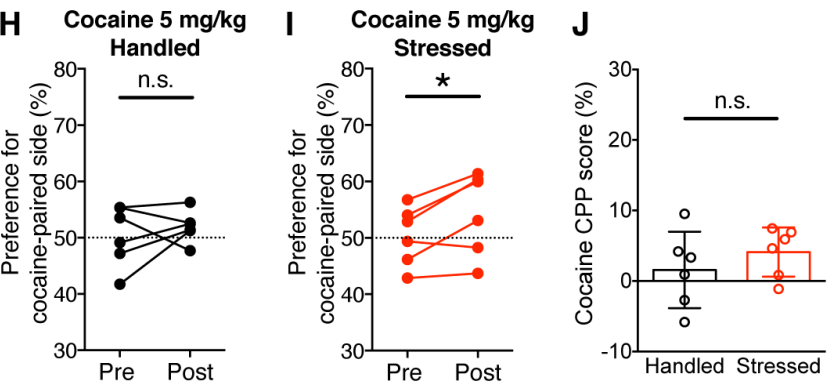

635 Figure 1. Acute exposure to social defeat stress enhances cocaine place conditioning

636 (A) Experimental timeline for testing the effect of acute social defeat stress on acquisition

637 of cocaine CPP.

638 (B-E) Changes in the preference for the cocaine-paired side in handled control rats and

639 stressed rats conditioned with $5 \mathrm{mg} / \mathrm{kg}$ or $10 \mathrm{mg} / \mathrm{kg}$ cocaine $\left(\mathrm{B}: \mathrm{t}_{7}=3.14, \mathrm{p}<0.05 ; \mathrm{C}: \mathrm{t}_{7}\right.$

$640=9.61, \mathrm{p}<0.0001 ; \mathrm{D}: \mathrm{t}_{6}=9.97, \mathrm{p}<0.0001 ; \mathrm{E}: \mathrm{t}_{7}=9.82, \mathrm{p}<0.0001 ;$ two-tailed paired $\mathrm{t}-$

641 test).

642 (F) Summary graph demonstrating defeat stress-induced enhancement of sensitivity to

643 cocaine conditioning (stress: $\mathrm{F}_{1,27}=9.81, \mathrm{p}<0.01$; cocaine dose: $\mathrm{F}_{1,27}=49.3, \mathrm{p}<0.0001$;

644 stress $\times$ cocaine dose: $\mathrm{F}_{1,27}=10.62, \mathrm{p}<0.01$; two-way ANOVA). ${ }^{*} \mathrm{p}<0.05, * * * \mathrm{p}<$

6450.001 (Bonferroni post hoc test). 
646 (G) Experimental timeline for testing the effect of social defeat stress on cocaine CPP

647 after a $1.5-\mathrm{hr}$ interval.

648 (H and $\mathrm{I})$ Changes in the preference for the cocaine-paired side in rats that underwent

649 handling $(\mathrm{H})$ or social defeat (I) $1.5 \mathrm{hr}$ before cocaine conditioning $(5 \mathrm{mg} / \mathrm{kg})\left(\mathrm{H}: \mathrm{t}_{5}=\right.$

$650 \quad 0.71, \mathrm{p}=0.51 ; \mathrm{I}: \mathrm{t}_{5}=2.8, \mathrm{p}<0.05 ;$ two-tailed paired t-test).

651 (J) Graph illustrating the ineffectiveness of defeat stress on cocaine CPP with a prolonged

652 interval $\left(\mathrm{t}_{10}=0.96, \mathrm{p}=0.36\right.$; two-tailed unpaired $\mathrm{t}$-test $)$. 

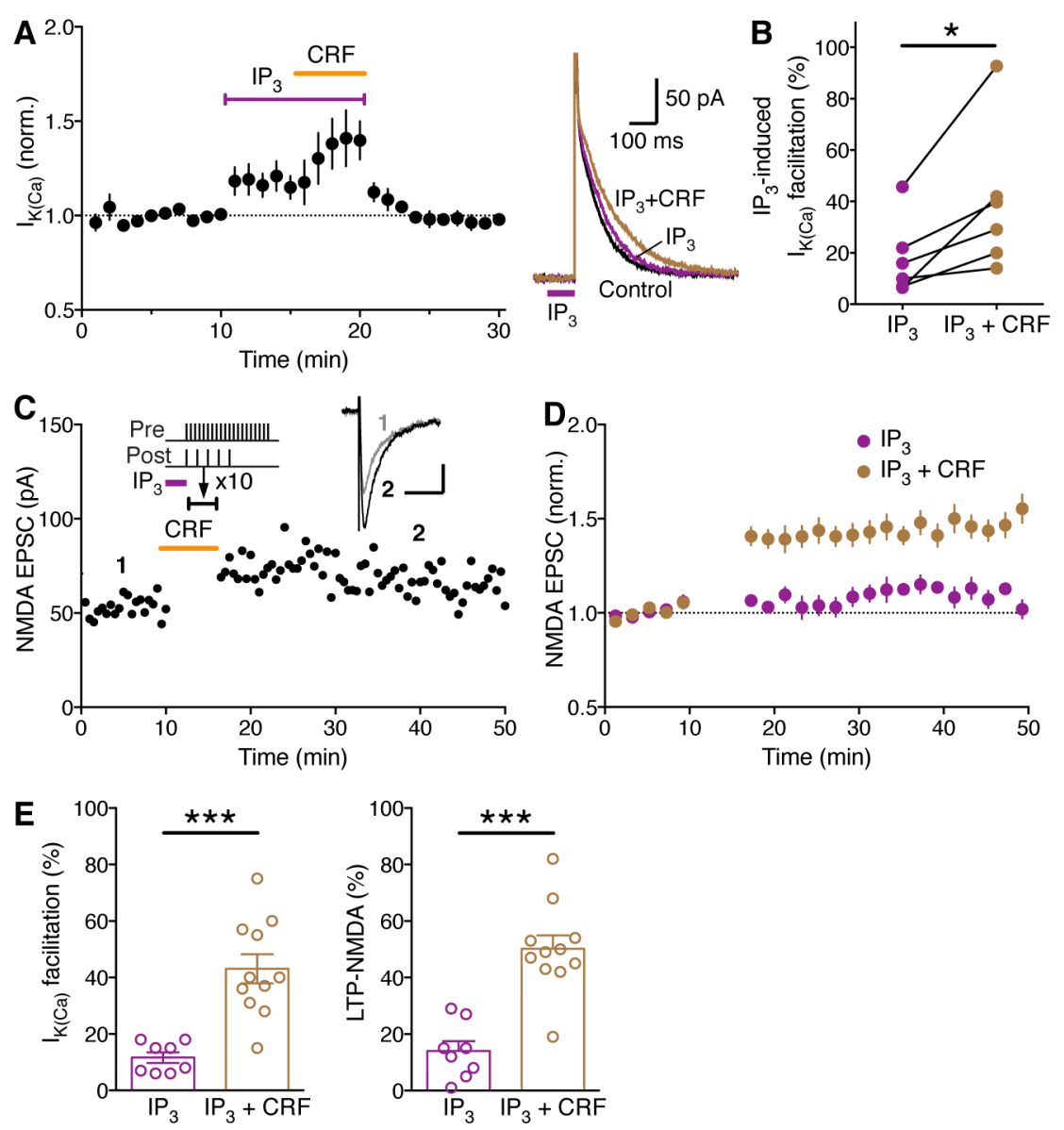

655 Figure 2. CRF enhances induction of LTP-NMDA driven by $\mathrm{IP}_{3}$-induced $\mathrm{Ca}^{2+}$ signal

\section{6 facilitation in VTA dopamine neurons}

657 (A) Summary time graph (left) and example traces (right) showing that bath application

658 of CRF $(100 \mathrm{nM})$ augments $\mathrm{IP}_{3}$-induced facilitation of AP-evoked $\mathrm{I}_{\mathrm{K}(\mathrm{Ca})}$. Subthreshold

659 level of $\mathrm{IP}_{3}$ (determined as shown in Figure 2-figure supplement 1) was photolytically

660 applied into the cytosol for $100 \mathrm{~ms}$ (purple bar in example traces) immediately before

661 evoking unclamped APs (6 cells from 4 rats).

662 (B) Graph plotting the magnitude of $\mathrm{IP}_{3}$-induced $\mathrm{I}_{\mathrm{KCa}}$ facilitation before and after CRF

663 application $\left(\mathrm{t}_{5}=3.29, \mathrm{p}<0.05\right.$, two-tailed paired t-test $)$.

664 (C) Representative experiment to induce LTP in the presence of CRF. CRF (100 nM) was

665 perfused for $\sim 6$ min after 10-min baseline EPSC recording, while the LTP induction 
666 protocol, which consisted of $\mathrm{IP}_{3}$-synaptic stimulation-burst combination (illustrated at the

667 top), was delivered at the time indicated (10 times every $20 \mathrm{~s}$; during a 3-min period

668 starting $\sim 3$ min after the onset of CRF perfusion to allow for CRF effect to take place; see

669 panel A). Example traces of NMDA EPSCs at times indicated are shown in inset (scale

670 bars: $50 \mathrm{~ms} / 20 \mathrm{pA})$.

671 (D) Summary time graph of LTP experiments in which LTP was induced using an $\mathrm{IP}_{3^{-}}$

672 synaptic stimulation-burst combination protocol in control solution (8 cells from 8 rats)

673 and in CRF (11 cells from 9 rats).

674 (E) Summary bar graphs depicting the magnitude of $\mathrm{I}_{\mathrm{k}(\mathrm{Ca})}$ facilitation (left) and LTP

675 (right) for the experiments shown in (D). $\mathrm{IP}_{3}$-induced facilitation of single AP-evoked

$676 \mathrm{I}_{\mathrm{K}(\mathrm{Ca})}$ was assessed by comparing the size of $\mathrm{I}_{\mathrm{K}(\mathrm{Ca})}$ with and without preceding $\mathrm{IP}_{3}$

677 application, which was done immediately before or after delivering the LTP induction

678 protocol $\left(\mathrm{I}_{\mathrm{k}(\mathrm{Ca})}\right.$ facilitation: $\mathrm{t}_{17}=5.01, \mathrm{p}<0.0001 ; \mathrm{LTP}: \mathrm{t}_{17}=5.70, \mathrm{p}<0.0001$; two-tailed 679 unpaired t-test).

680 

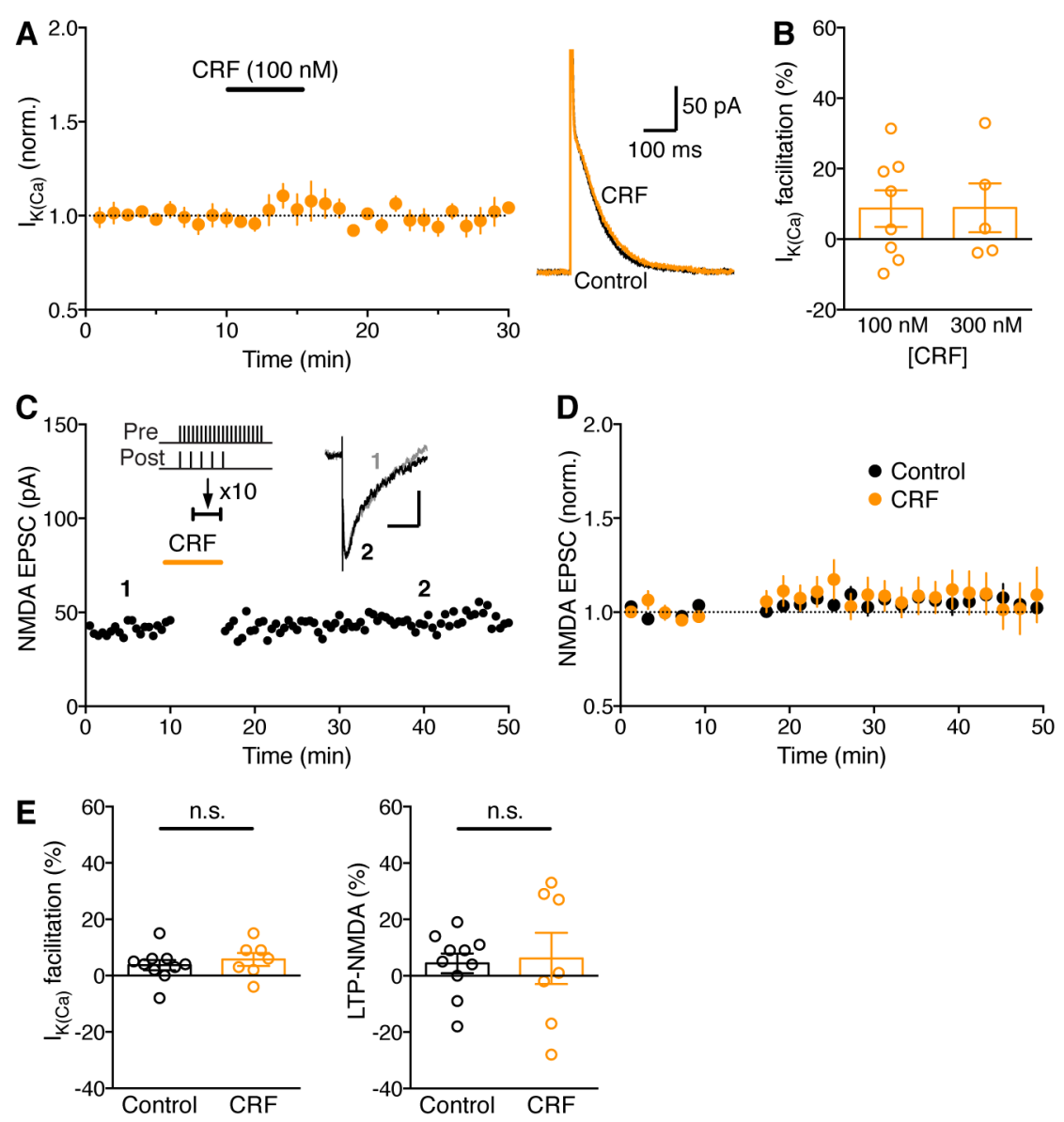

\section{Figure 3. CRF causes no LTP without $\mathrm{IP}_{3}$-induced $\mathrm{Ca}^{2+}$ signal facilitation}

683 (A) Summary time graph (left) and example traces (right) illustrating that CRF (100 nM)

684 has small effect on $\mathrm{I}_{\mathrm{K}(\mathrm{Ca})}$ without preceding $\mathrm{IP}_{3}$ application (8 cells from 7 rats).

685 (B) Summary bar graph showing the magnitude of $\mathrm{I}_{\mathrm{K}(\mathrm{Ca})}$ facilitation produced by two 686 concentrations of CRF (300 nM: 5 cells from 4 rats).

687 (C) Representative experiment to induce LTP in the presence of CRF using an induction 688 protocol consisting of synaptic stimulation-burst pairing with no preceding $\mathrm{IP}_{3}$ 689 application. Example EPSC traces at the times indicated are shown in inset (scale bars: $69050 \mathrm{~ms} / 20 \mathrm{pA})$. 
691 (D) Summary time graph of LTP experiments in which LTP was induced using a synaptic

692 stimulation-burst pairing protocol in control solution (10 cells from 10 rats) and in CRF

693 (7 cells from 7 rats).

694 (E) Summary bar graphs depicting the magnitude of $\mathrm{I}_{\mathrm{k}(\mathrm{Ca})}$ facilitation (left) and LTP

695 (right) for the experiments shown in (D). $\mathrm{I}_{\mathrm{K}(\mathrm{Ca})}$ facilitation was assessed by comparing the

696 size of single AP-evoked $\mathrm{I}_{\mathrm{K}(\mathrm{Ca})}$ measured immediately after 10-min baseline EPSC

697 recording with that measured immediately before or after LTP induction $\left(\mathrm{I}_{\mathrm{k}(\mathrm{Ca})}\right.$

698 facilitation: $\mathrm{t}_{15}=0.70, \mathrm{p}=0.50 ; \mathrm{LTP}: \mathrm{t}_{15}=0.20, \mathrm{p}=0.84$; two-tailed unpaired t-test).

699 

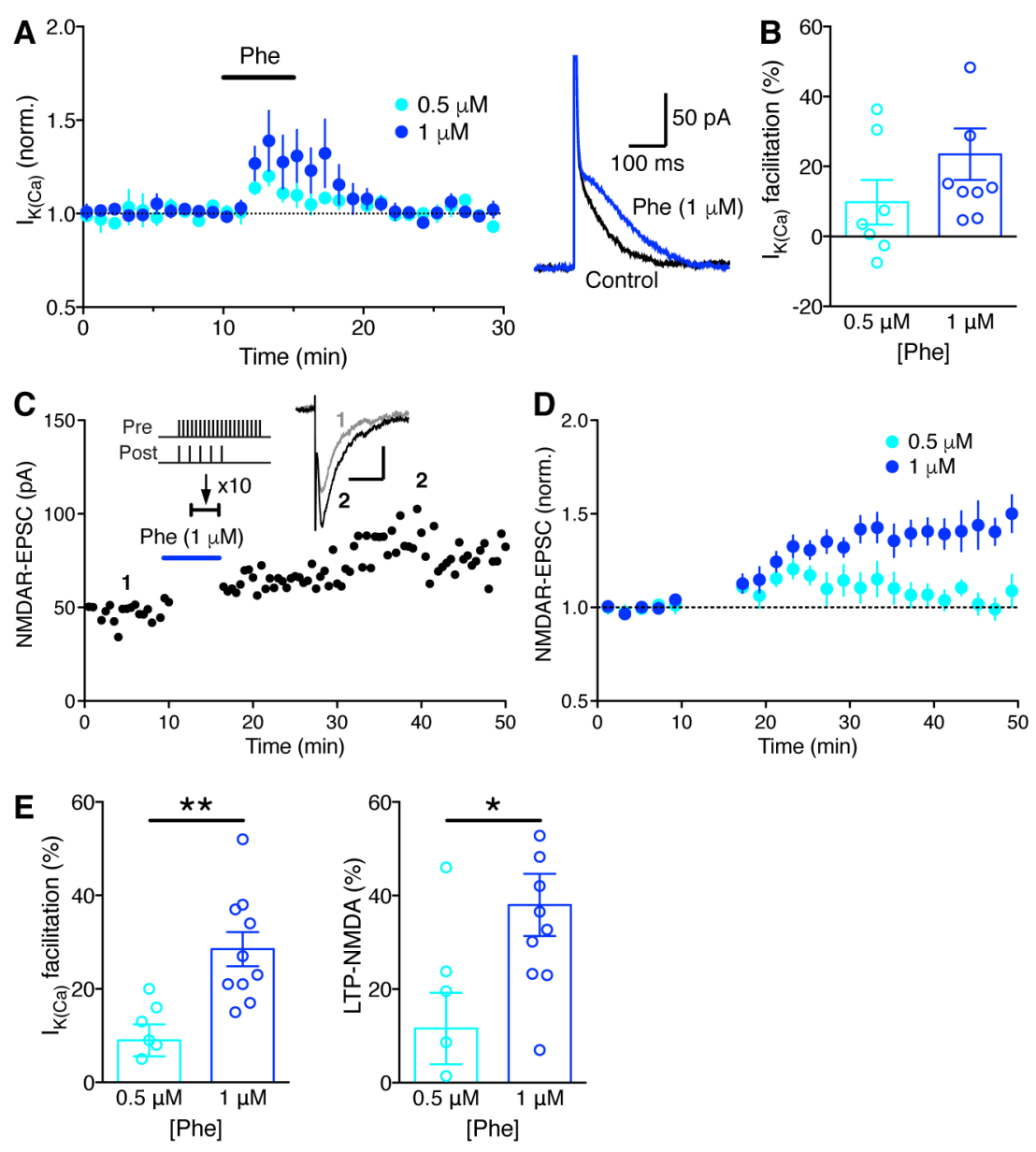

701 Figure 4. $\alpha 1 A R$ agonist phenylephrine enables LTP without IP $_{3}$-induced $\mathrm{Ca}^{2+}$ signal

\section{2 facilitation}

703 (A) Summary time graph (left) and example traces (right) depicting the facilitatory effect

704 of two concentrations of phenylephrine on $\mathrm{I}_{\mathrm{K}(\mathrm{Ca})}(0.5 \mu \mathrm{M}: 7$ cells from 3 rats; $1 \mu \mathrm{M}: 9$

705 cells from 6 rats).

706 (B) Summary bar graph showing the magnitude of phenylephrine-induced $\mathrm{I}_{\mathrm{K}(\mathrm{Ca})}$

707 facilitation.

708 (C) Representative experiment to induce LTP-NMDA in the presence of phenylephrine

$709(1 \mu \mathrm{M})$ using an induction protocol consisting of synaptic stimulation-burst pairing with 
710 no preceding $\mathrm{IP}_{3}$ application. Example EPSC traces at the times indicated are shown in

711 inset (scale bars: $50 \mathrm{~ms} / 20 \mathrm{pA})$.

712 (D) Summary time graph of LTP experiments in which LTP was induced using a synaptic

713 stimulation-burst pairing protocol in the presence of $0.5 \mu \mathrm{M}$ or $1 \mu \mathrm{M}$ phenylephrine $(0.5$

$714 \mu \mathrm{M}$ : 7 cells from 7 rats; $1 \mu \mathrm{M}$ : 10 cells from 8 rats).

715 (E) Summary bar graphs depicting the magnitude of $\mathrm{I}_{\mathrm{k}(\mathrm{Ca})}$ facilitation (left) and LTP

716 (right) for the experiments shown in (D). $\mathrm{I}_{\mathrm{K}(\mathrm{Ca})}$ facilitation was assessed by comparing the

717 size of single AP-evoked $\mathrm{I}_{\mathrm{K}(\mathrm{Ca})}$ measured immediately after 10-min baseline EPSC

718 recording with that measured immediately before or after LTP induction $\left(\mathrm{I}_{\mathrm{k}(\mathrm{Ca})}\right.$

719 facilitation: $\mathrm{t}_{15}=3.72, \mathrm{p}<0.01$; LTP: $\mathrm{t}_{15}=2.59, \mathrm{p}<0.05$; two-tailed unpaired $\mathrm{t}$-test). 

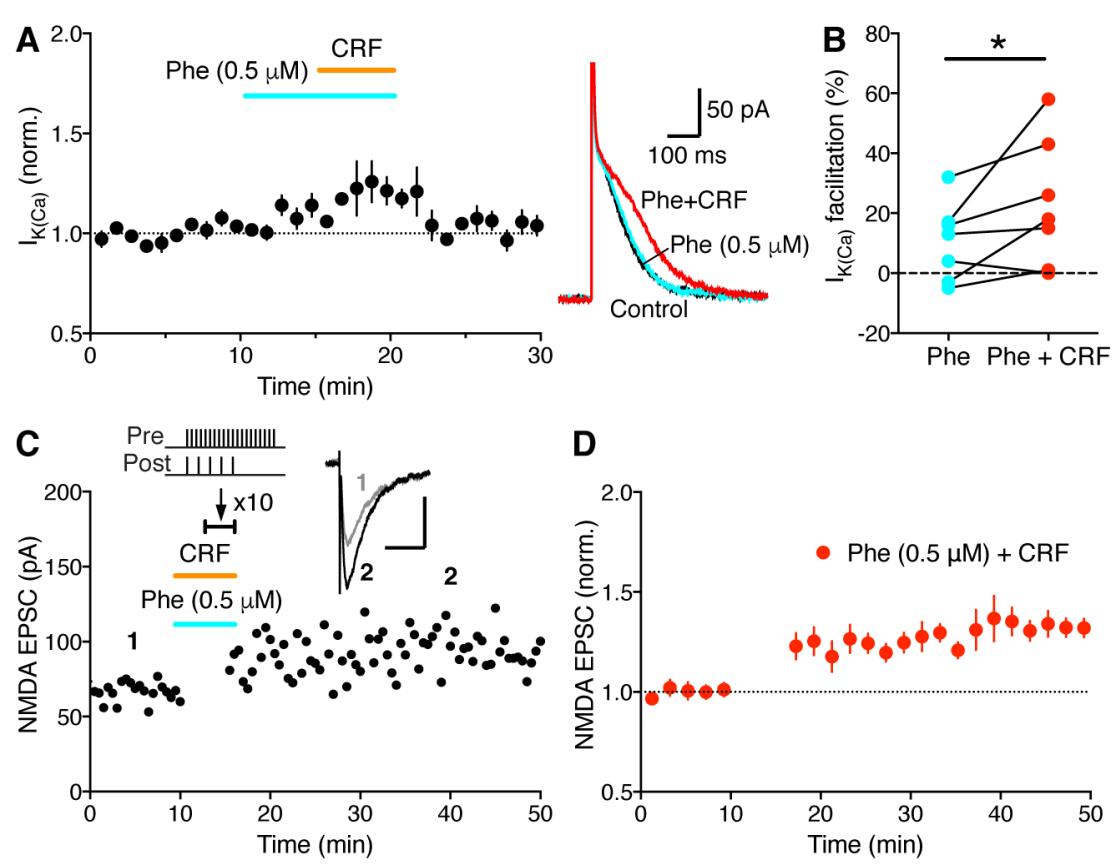

723 Figure 5. CRF synergizes with phenylephrine to drive LTP without IP $_{3}$-induced

\section{$724 \mathbf{C a}^{2+}$ signal facilitation}

725 (A) Summary time graph (left) and example traces (right) showing that CRF augments

726 facilitation of AP-evoked $\mathrm{I}_{\mathrm{K}(\mathrm{Ca})}$ produced by a low concentration $(0.5 \mu \mathrm{M})$ of

727 phenylephrine (7 cells from 5 rats).

728 (B) Graph plotting the magnitude of $\mathrm{I}_{\mathrm{KCa}}$ facilitation caused by phenylephrine $(0.5 \mu \mathrm{M})$

729 alone and by CRF + phenylephrine in individual cells $\left(\mathrm{t}_{6}=2.22, \mathrm{p}<0.05\right.$, two-tailed

730 paired t-test).

731 (C) Representative experiment to induce LTP in the presence of both CRF and

732 phenylephrine $(0.5 \mu \mathrm{M})$ using an induction protocol consisting of synaptic stimulation-

733 burst pairing with no preceding $\mathrm{IP}_{3}$ application. Example EPSC traces at the times

734 indicated are shown in inset (scale bars: $50 \mathrm{~ms} / 50 \mathrm{pA}$ ). 
735 (D) Summary time graph of LTP experiments in which LTP was induced using a synaptic

736 stimulation-burst pairing protocol in the presence of both CRF and phenylephrine $(0.5$

$737 \mu \mathrm{M})(7$ cells from 4 rats).

738
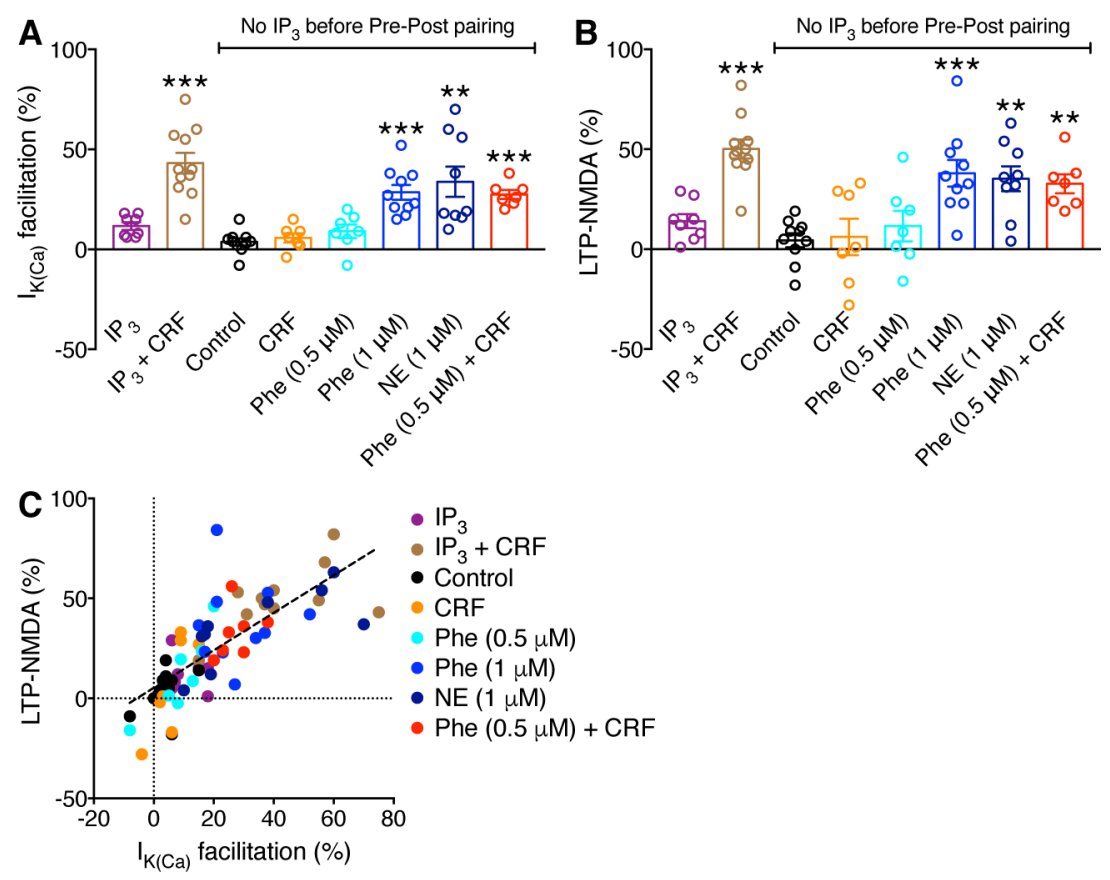

739

\section{Figure 6. Summary of LTP experiments}

741 (A and B) Summary bar graphs demonstrating the magnitude of $\mathrm{I}_{\mathrm{k}(\mathrm{Ca})}$ facilitation (A) and

742 LTP (B) for all LTP experiments testing CRF, phenylephrine, and NE (A: $F_{7,60}=13.2, p$

$743<0.0001 ; \mathrm{B}: \mathrm{F}_{7,60}=9.07, \mathrm{p}<0.0001$; one-way ANOVA). ${ }^{*} \mathrm{p}<0.01, * * * \mathrm{p}<0.001$ vs.

744 control group with no $\mathrm{IP}_{3}$ (Dunnett's post hoc test). CRF, phenylephrine, and NE had no

745 effect on NMDA transmission itself (Figure 6-figure supplement 1). (C) The magnitude

746 of LTP is plotted versus the magnitude of $\mathrm{I}_{\mathrm{k}(\mathrm{Ca})}$ facilitation in individual neurons. Dashed

747 line is a linear fit to all data points $\left(n=69, r^{2}=0.56\right)$. 
A

Injection of antagonists into VTA

$\downarrow^{10} \mathrm{~min}$

Handling or social defeat stress (30 min)
Pretest $\longrightarrow$ Saline conditioning $\longrightarrow$ Cocaine conditioning $\longrightarrow$ Posttest
$\begin{aligned} & \downarrow^{10} \text { min } \\ & (5 \mathrm{mg} / \mathrm{kg})\end{aligned}$

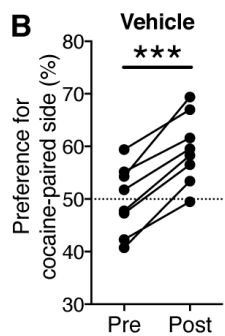
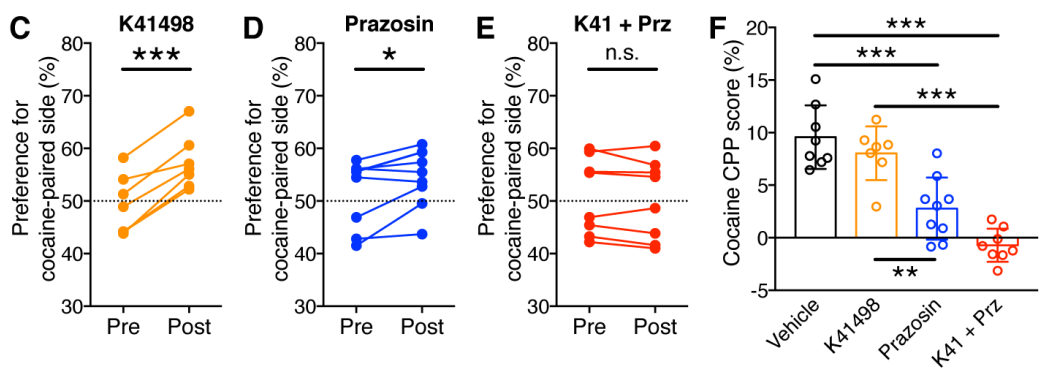

G

Injection of agonists into VTA

Pretest $\longrightarrow$ Saline conditioning $\longrightarrow$ Cocaine conditioning $\longrightarrow$ Posttest $(5 \mathrm{mg} / \mathrm{kg})$
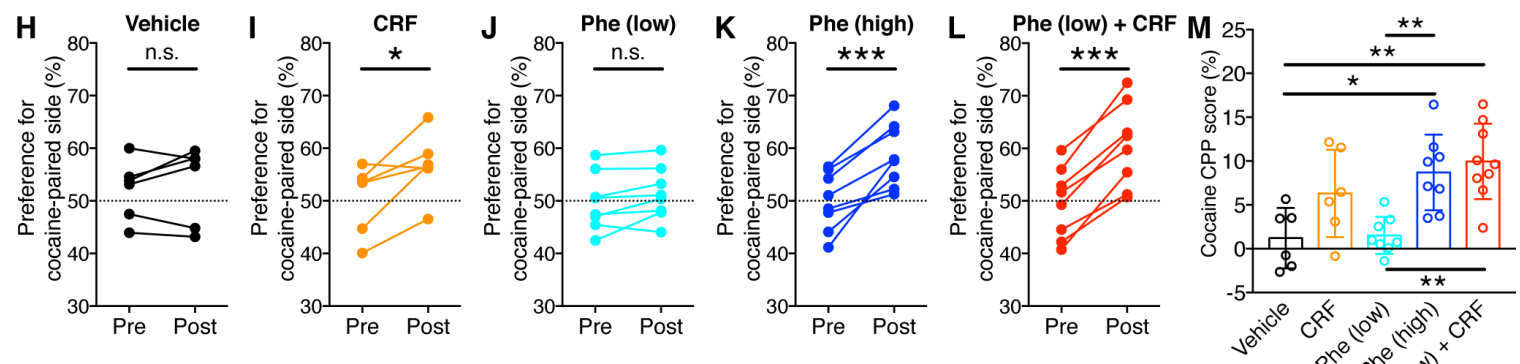

749

750 Figure 7. CRF and NE acting on CRFR2 and $\alpha 1 A R$ in the VTA synergistically

751 promote cocaine place conditioning

752 (A) Experimental timeline for testing the effects of intra-VTA injection of CRFR2

753 antagonist K41498 and $\alpha 1 \mathrm{AR}$ antagonist prazosin on defeat stress-induced enhancement

754 of cocaine conditioning.

755 (B-E) Changes in the preference for the cocaine-paired side (conditioned with $5 \mathrm{mg} / \mathrm{kg}$

756 cocaine) in socially defeated rats that received intra-VTA injection of PBS (B), K41498

757 (C), prazosin (D), or a cocktail of K41498 and prazosin (E) $\left(H: t_{7}=8.97, p<0.0001 ; \mathrm{I} \mathrm{t}_{7}\right.$

$758=4.03, \mathrm{p}<0.01 ; \mathrm{J}: \mathrm{t}_{8}=2.82, \mathrm{p}<0.05 ; \mathrm{K}: \mathrm{t}_{7}=1.27, \mathrm{p}=0.24 ;$ two-tailed paired $\mathrm{t}$-test). 
759 (F) Summary graph demonstrating CRFR2 and $\alpha 1 \mathrm{AR}$ dependence of stress-induced

760 enhancement of cocaine conditioning $\left(\mathrm{F}_{3,30}=14.5, \mathrm{p}<0.0001\right.$, one-way ANOVA $) . * * \mathrm{p}<$

$761 \quad 0.01, * * * \mathrm{p}<0.001$ (Bonferroni post hoc test).

762 (G) Experimental timeline for testing the effects of intra-VTA injection of CRF and

763 phenylephrine on acquisition of cocaine CPP in non-stressed rats.

$764(\mathrm{H}-\mathrm{L})$ Changes in the preference for the cocaine-paired side (conditioned with $5 \mathrm{mg} / \mathrm{kg}$

765 cocaine) in rats that received intra-VTA injection of PBS (H), CRF (I), high-dose

766 phenylephrine $(18 \mathrm{pmol} / 0.3 \mu \mathrm{L} ; \mathrm{J})$, low-dose phenylephrine $(6 \mathrm{pmol} / 0.3 \mu \mathrm{L}$; K), or a

767 cocktail of CRF and low-dose phenylephrine (L) $\left(B: t_{7}=0.40, p=0.70 ; C: t_{7}=2.28, p=\right.$

$7680.057 ; \mathrm{D}: \mathrm{t}_{7}=5.69, \mathrm{p}<0.001 ; \mathrm{E}: \mathrm{t}_{7}=2.02, \mathrm{p}=0.083 ; \mathrm{F}: \mathrm{t}_{7}=8.89, \mathrm{p}<0.0001 ;$ two-tailed

769 paired t-test).

770 (M) Summary graph demonstrating the effects of CRF and phenylephrine on cocaine

771 place conditioning in the absence of stress $\left(\mathrm{F}_{4,36}=5.17, \mathrm{p}<0.01\right.$, one-way ANOVA $)$ * $\mathrm{p}$

$772<0.05, * * \mathrm{p}<0.01$ (Bonferroni post hoc test).

773 
A

Handling or social defeat stress (30 $\mathrm{min}$ )
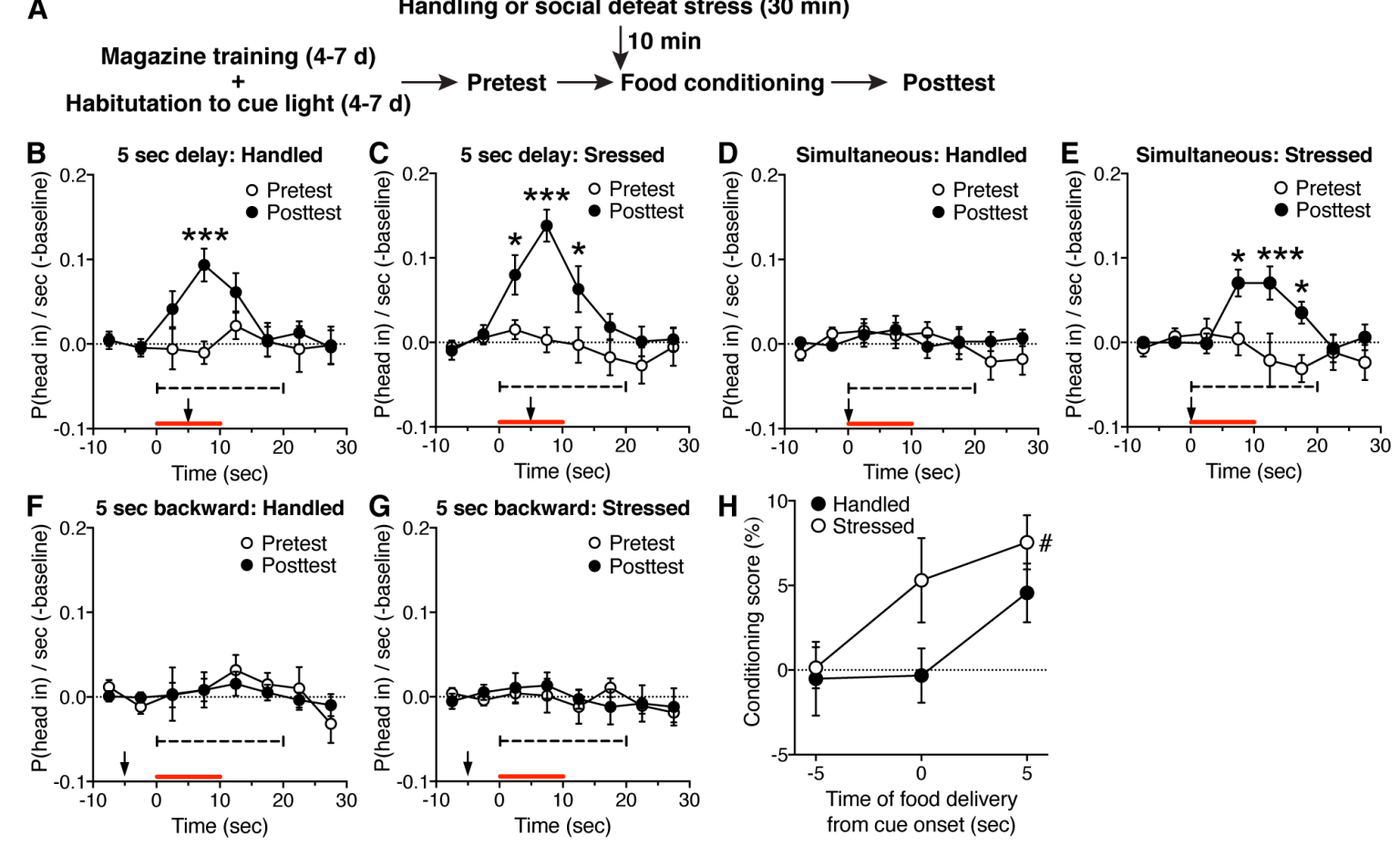

Figure 8. Acute social defeat stress enables learning of a food-paired cue with no

(A) Experimental timeline for testing the effect of acute social defeat stress on food conditioned approach. of food delivery during conditioning (B: time: $\mathrm{F}_{7,56}=3.30, \mathrm{p}<0.01$; time $\times$ test: $\mathrm{F}_{7,56}=$

783 2.31, $p<0.05$; C: time: $F_{7,70}=7.22, p<0.0001$; test: $F_{1,10}=19.2, p<0.01$; time $\times$ test:

$784 \mathrm{~F}_{7,70}=4.81, \mathrm{p}<0.001 ; \mathrm{E}:$ time: $\mathrm{F}_{7,70}=3.34, \mathrm{p}<0.01 ;$ time $\times$ test: $\mathrm{F}_{7,56}=3.30, \mathrm{p}<0.01$

785 repeated measures two-way ANOVA). (H) Summary graph illustrating the cue-reward

786 timing dependence of conditioning in control and stressed rats (time of food: $F_{2,56}=5.33$,

$787 \mathrm{p}<0.01$; stress: $\mathrm{F}_{1,56}=4.09, \mathrm{p}<0.05$; two-way ANOVA). Conditioning score (expressed 
788 in \%) was calculated from the $20 \mathrm{sec}$ period at the dashed line in (B) $-(\mathrm{G}) .{ }^{*} \mathrm{p}<0.05$,

$789 * * * \mathrm{p}<0.001$ vs. pretest in (B), (C), and (E); ${ }^{*} \mathrm{p}<0.05$ vs. $-5 \mathrm{sec}$ group in $(\mathrm{H})$ (Bonferroni

790 post hoc test).

791 

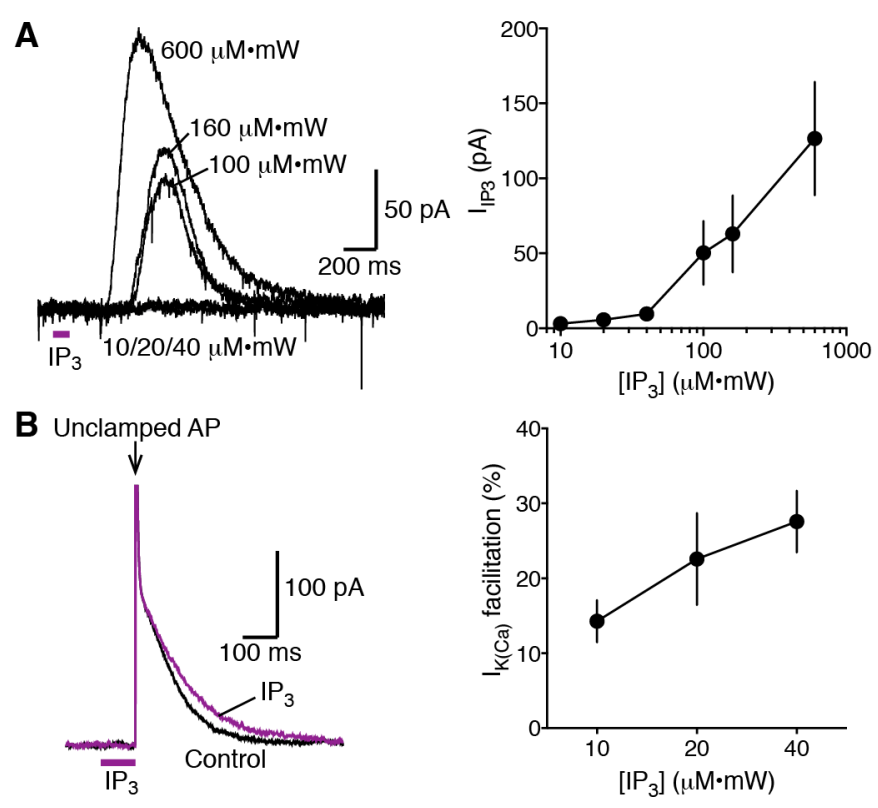

\section{Figure 2-figure supplement 1.}

795 (A) Example traces and summary graph depicting the concentration dependence of $\mathrm{IP}_{3^{-}}$

796 evoked outward currents. Data were obtained from 7 cells, where six different $\mathrm{IP}_{3}$

797 concentrations $(10,20,40,100,160$, and $600 \mu \mathrm{M} \cdot \mathrm{mW}$; photolytically applied for 100

$798 \mathrm{~ms})$ were tested in each cell.

799 (B) Example traces (using $40 \mu \mathrm{M} \cdot \mathrm{mW} \mathrm{IP}_{3}$ ) and summary graph illustrating facilitation of

800 AP-evoked $\mathrm{I}_{\mathrm{K}(\mathrm{Ca})}$ caused by near-threshold levels of $\mathrm{IP}_{3}(10,20$, and $40 \mu \mathrm{M} \cdot \mathrm{mW} ; \mathrm{n}=14$,

8017 , and 7, respectively). Note the relatively long latency ( $\sim 200-400 \mathrm{~ms})$ following $\mathrm{IP}_{3}$

802 application to evoke response at suprathreshold range $(100,160$, and $600 \mu \mathrm{M} \cdot \mathrm{mW})$,

803 which reflects the time required to engage the regenerative $\mathrm{IP}_{3} \mathrm{R}$-mediated $\mathrm{Ca}^{2+}$-induced

$804 \mathrm{Ca}^{2+}$ release process. In contrast, $\mathrm{IP}_{3}$ effect on AP-evoked $\mathrm{I}_{\mathrm{K}(\mathrm{Ca})}$ occurs with no latency, as

805 rapid $\mathrm{Ca}^{2+}$ influx triggered by APs initiates the $\mathrm{Ca}^{2+}$-induced $\mathrm{Ca}^{2+}$ release process, which

806 can be augmented by near-threshold levels of $\mathrm{IP}_{3}$. 

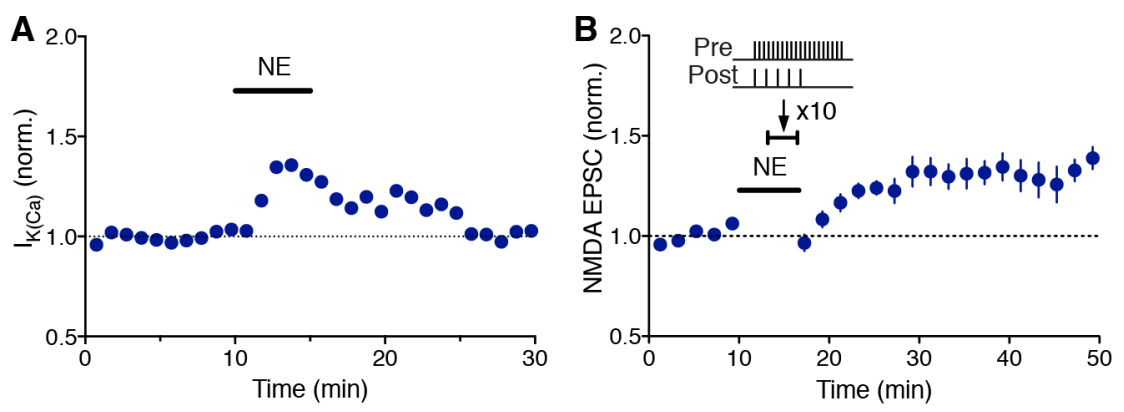

809 Figure 4-figure supplement 1.

810 (A) Summary time graph showing the facilitatory effect of NE $(1 \mu \mathrm{M})$ on AP-evoked

$811 \mathrm{I}_{\mathrm{K}(\mathrm{Ca})}(\mathrm{n}=5)$.

812 (B) Summary time graph of LTP-NMDA experiments in which LTP was induced using a

813 synaptic stimulation-burst pairing protocol in the presence of NE $(1 \mu \mathrm{M} ; \mathrm{n}=9)$.

814

815
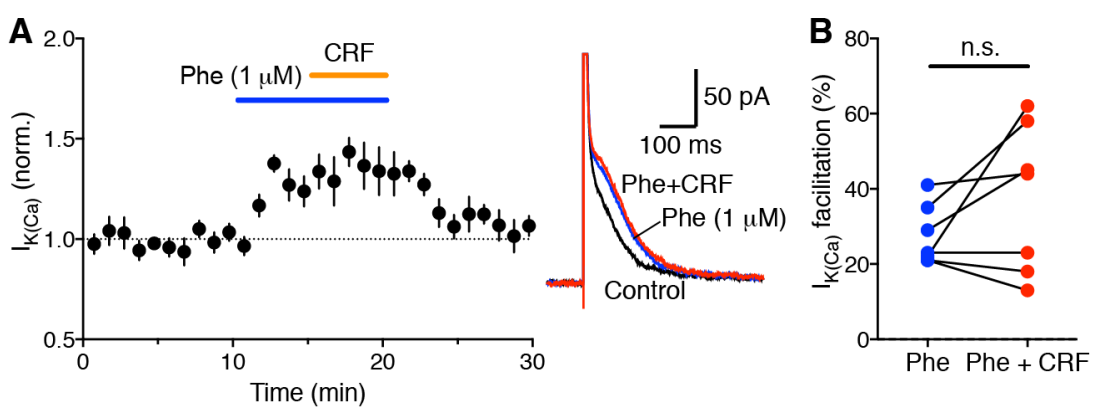

816 Figure 5-figure supplement 1.

817 (A) Summary time graph (left) and example traces (right) showing that CRF does not

818 have significant effect on AP-evoked $\mathrm{IK}(\mathrm{Ca})$ facilitated by a high concentration $(1 \mu \mathrm{M})$

819 of phenylephrine $(\mathrm{n}=9)$.

820 (B) Graph plotting the magnitude of $\mathrm{IK}(\mathrm{Ca})$ facilitation caused by phenylephrine $(1 \mu \mathrm{M})$

821 alone and by CRF + phenylephrine in individual cells $\left(\mathrm{t}_{6}=1.57, \mathrm{p}=0.17\right.$, two-tailed

822 paired t-test). 

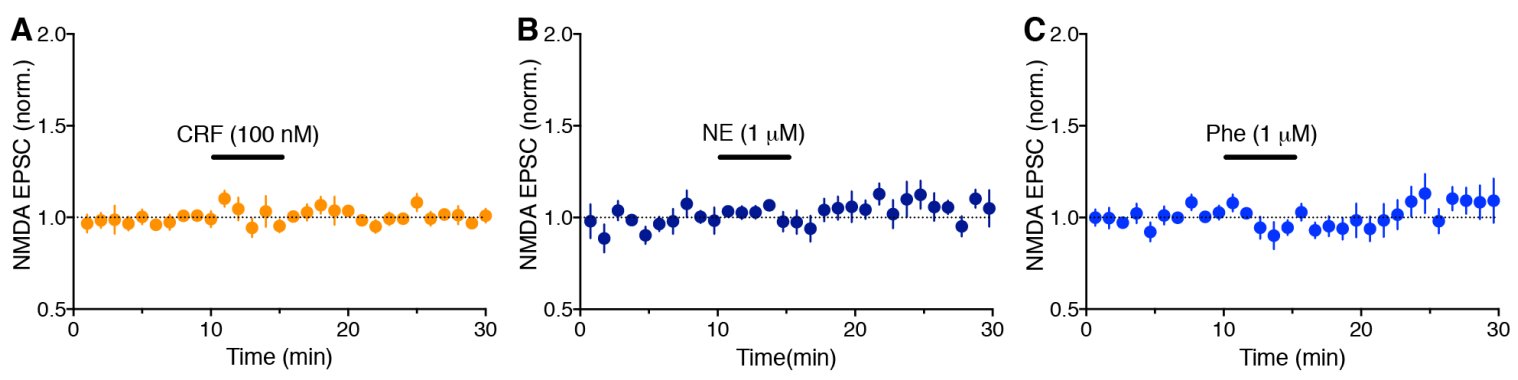

\section{Figure 6-figure supplement 1.}

826 Summary time graphs showing that CRF $(A: n=5)$, NE $(B: n=7)$, and phenylephrine

$827(\mathrm{C}: \mathrm{n}=5)$ have no measurable effect on NMDA EPSCs.

828
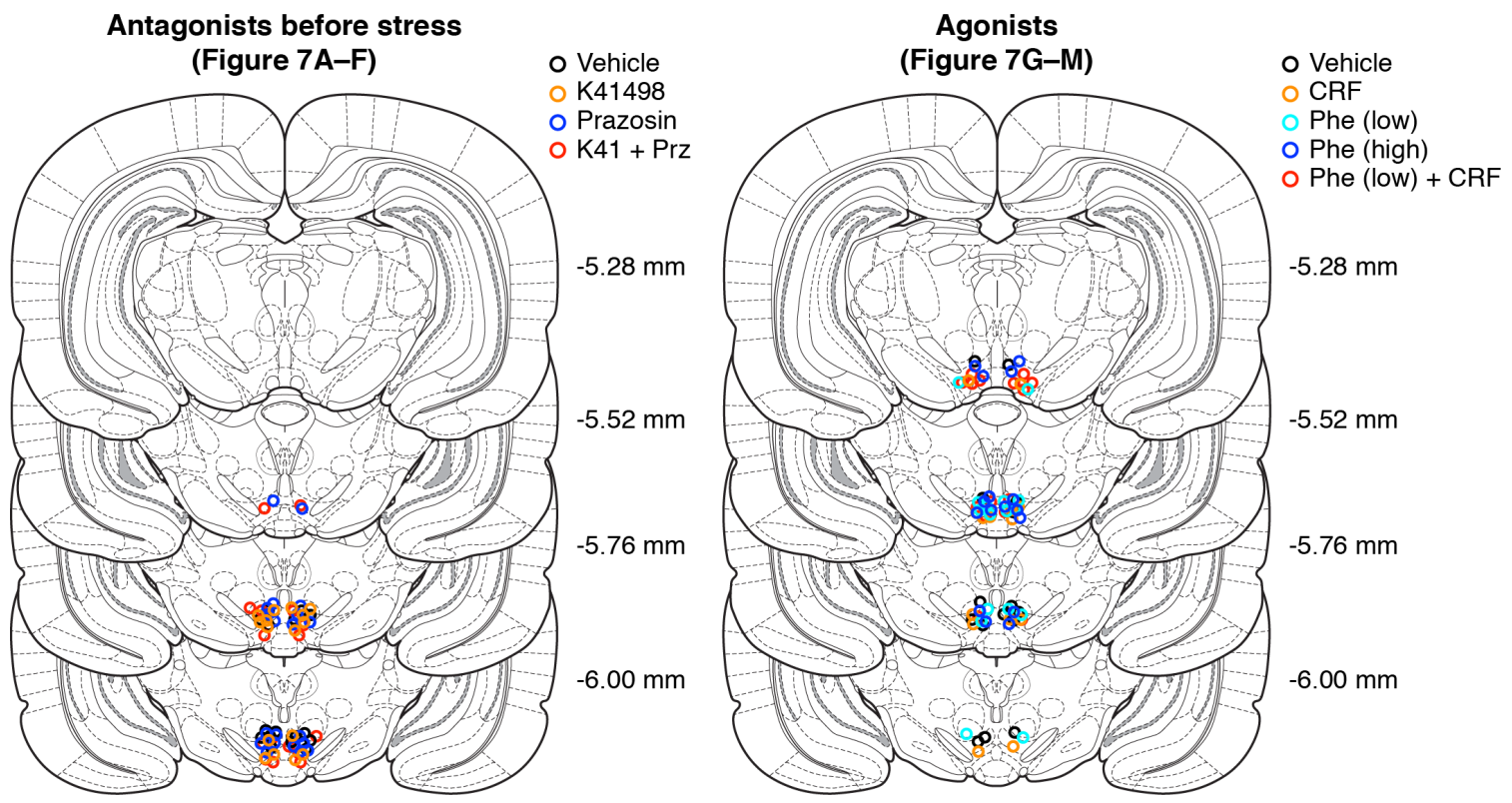

$830 \quad$ Figure 7-figure supplement 1.

831 Approximate locations (mm from bregma) of cannula tips for intra-VTA microinjection

832 experiments in Figure 7. 

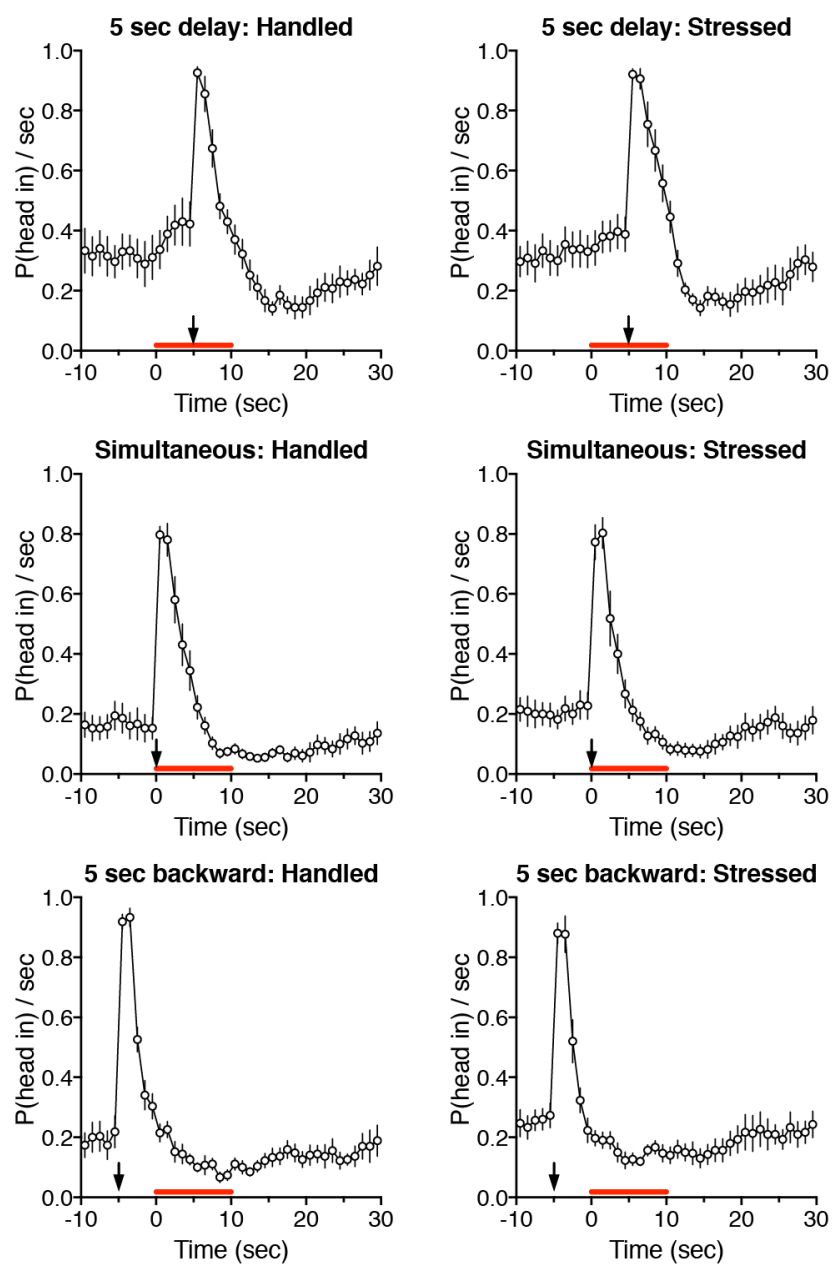

Figure 8-figure supplement 1.

836 Time graphs illustrating head entry responses during conditioning sessions. The $10 \mathrm{sec}$

837 cue light was presented at the red bar, while food was delivered at arrow. 

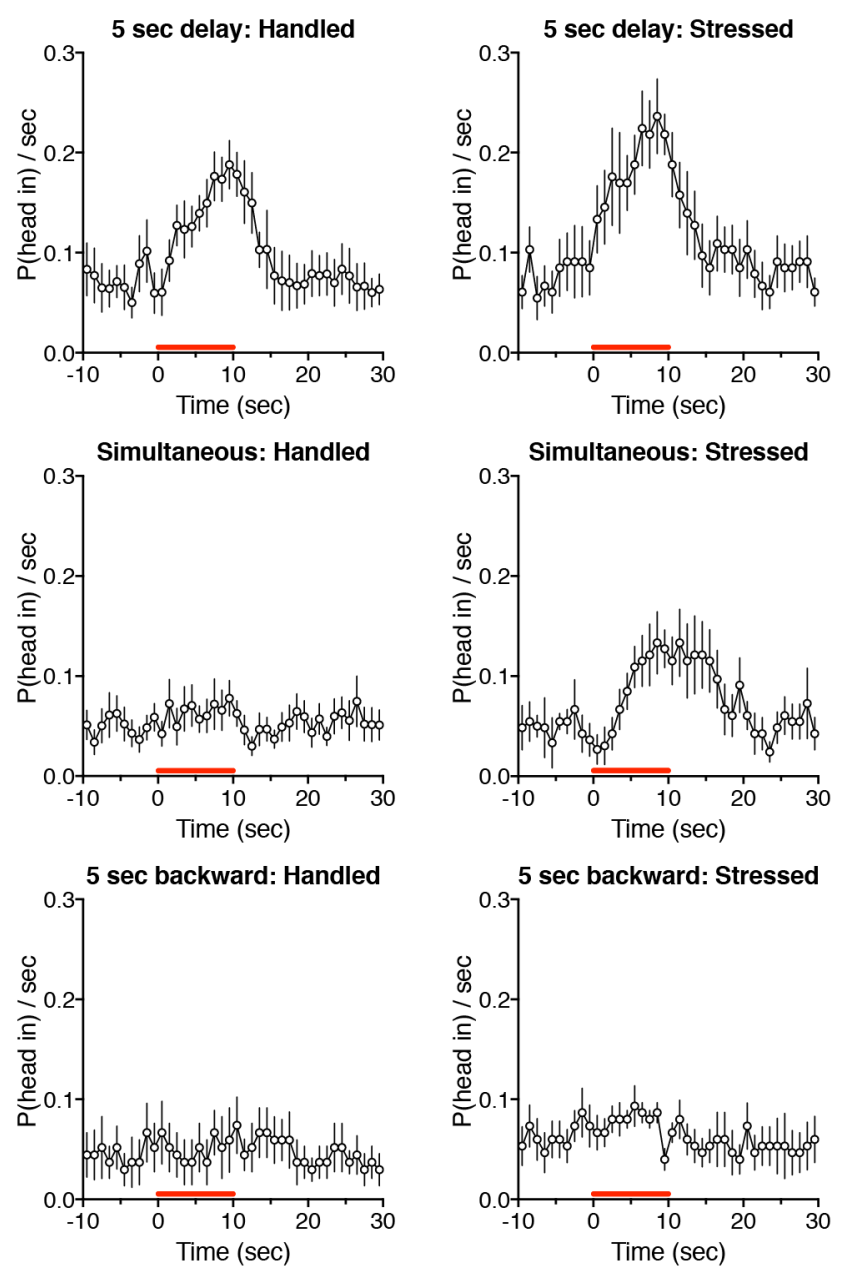

\section{$840 \quad$ Figure 8-figure supplement 2.}

841 Time graphs illustrating head entry responses during posttests. The $10 \mathrm{sec}$ cue light was

842 presented at the red bar.

843 
A

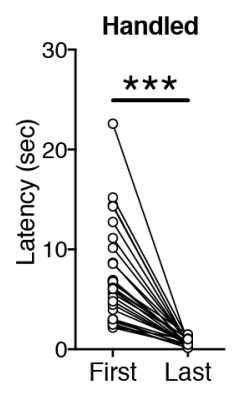

B

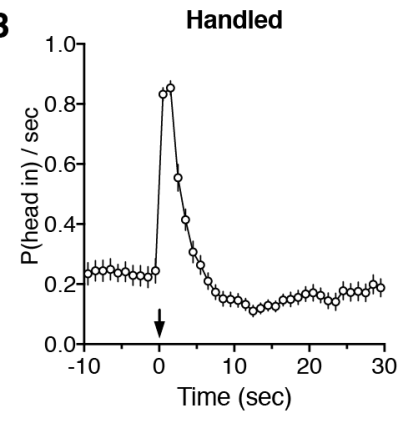

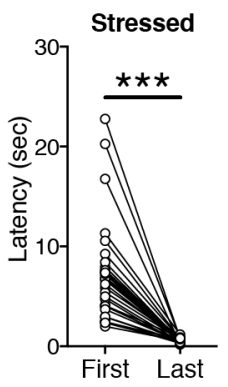

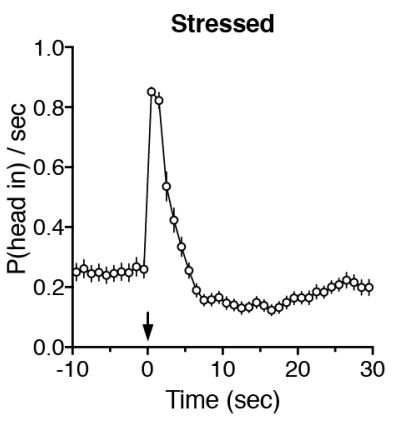

$845 \quad$ Figure 8-figure supplement 3.

846 Graphs depicting head entry responses during magazine training sessions before

847 undergoing handling/social defeat and conditioning sessions.

848 (A) Mean latency to the first head entry after food delivery is plotted during the first and

849 last magazine training sessions in individual rats. Data are from all rats shown in Figure 8

850 (handled: $\mathrm{t}_{29}=7.52, \mathrm{p}<0.0001$; stressed: $\mathrm{t}_{31}=7.53, \mathrm{p}<0.0001$; paired $\mathrm{t}$-test).

851 (B) Time graphs plotting the probability of head entry into the food magazine during the

852 last magazine training session. Food was delivered at arrow. 